\title{
La «regula fidei» en la teología de San Agustín
}

"Tu es ergo regula veritatis?"

Contra Fausto 11,2

INTRODUCCIÓN

«La Iglesia ha considerado como suprema norma de su fe la Escritura unida a la Tradición, ya que, inspirada por Dios y escrita de una vez para siempre, nos transmite inmutablemente la palabra del mismo Dios, y en las palabras de los Apóstoles y de los Profetas hace resonar la voz del Espíritu Santo» (D.V. 21). En efecto, la normatividad de la fe es un tema que nos sitúa en la dinámica de la revelación de Dios al hombre. Ella reclama una conciencia codificante, en definiciones dogmáticas, como fuerza de conservación, llegando a constituirse en un principio de continuidad y de identidad de un espíritu a través del sucederse de las generaciones. Exige, pues, una fidelidad al mensaje revelado por Dios en la historia, cual regla de fe.

La regla de la fe es inmanente al objeto de fe, pues «la autoridad de la Iglesia, que procede de Dios y se encuentra atestada en la Revelación, interviene en el proceso de comunicación que viene de Dios a nosotros y que es el modo teologal de la fe intrínsecamente regido por la Palabra de Dios» ${ }^{1}$.

Por otra parte, «si tal regla existe en documentos escritos -símbolos, cánones de los concilios, escritos de los santos Padres, liturgia-, ella vive en la Iglesia y no es separable de la "ecclesia" que es el sujeto vivo» ${ }^{2}$. Tal principio nos pone de frente a problemas actuales como el cuestionamiento de la

1 Y. CONGAR, La Tradizione e la vita della Chiesa, Roma 1983, p. 77.

2 Idem, p. 84. 
función normativa del Magisterio de la Iglesia ${ }^{3}$ que se escucha de diversos y variados sectores de la misma ${ }^{4}$, el fundamentalismo de las sectas cristianas o de los "grupos" eclesiales (neo-catecumenales, comunidades de base, etc.) generadores de nuevos cismas o pseudo-cismas, el sacerdocio femenino provocación al ecumenismo ${ }^{5}$, etc.. Precisamente ante este panorama nos podemos preguntar en qué medida la Escritura-Tradición-Magisterio conservan un valor normativo en la vida cristiana: ¿Existe una regla de fe que pueda conservar por una parte la fidelidad a la Revelación y por otra, fidelidad al Hombre y a la Cultura de nuestro tiempo?

Este es el trasfondo en el que nos acercamos al pensamiento agustiniano «cuya orientación de la investigación, a la que nutría incesantemente el amor, tuvo dos coordenadas: una mayor comprensión de la fe católica y su defensa contra quienes la negaban, como eran los maniqueos y los paganos, o daban de ella interpretaciones equivocadas, como los donatistas, pelagianos y arrianos» ${ }^{6}$. Su situación histórica análogamente semejante a la nuestra ${ }^{7}$ nos permite dirigirnos a él como Maestro, ya que como dice Erich Przy-

3 Cf. las colaboraciones en Asprenas. Rivista di Scienze Teologiche 37 (1990): G. MATTAI, «Magistero e Teologia: alle radici di un dissenso» (pp. 27-40) y S. CIPRIANI, «Magistero e Teologia: un difficile ma ineludibile rapporto» (pp. 41-58). El primero presenta una evaluación del problema de la normatividad de fe en la actualidad, proponiéndolo en términos conflictivos. El segundo, por su parte, trata de conciliar las posiciones divergentes entre teólogos y Magisterio, cual norma de fe, aún del progreso teológico.

4 Se piense a la posición crítica de los enfrentamientos de la Congregación para la Doctrina de la Fe ante las teologías de la liberación [cf. los pronunciamientos de la misma Congregación: Instrucción sobre algunos aspectos de la Teología de la Liberación (1984) y Libertad cristiana y Liberación (1986)], así como las Declaraciones de los 163 teólogos de Colonia [«Por una catolicidad abierta y contra una catolicidad puesta bajo tutela» (1989)]; de los teólogos italianos (1989); la de los 120 teólogos brasileños [«Documento de Victoria: La barca en la Tempestad» (1989)]. También pensamos a la posición pastoral de la Conferencia Episcopal Norteaméricana (NCCB) ante la Santa Sede respecto a problemas matrimoniales; las declaraciones de B. Häring sobre moral cristiana; o bien, el Documento «Kairós» del Cristianismo sudafricano (1986), etc..

5 «Il vero problema da affrontare, tanto a livello anglicano quanto a livello di dialogo ecumenico, è quello dell'autorità con particolare attenzione a chi la esercita e con quali strumenti la si esercita»: P. GAMBERINI, «La Conferenza di Lambeth '88», en La Civiltà Cattolica 139 (1988), 473-480, p. 476.

6 Ioannes Paulus II, Epistula Apostolica "Augustinum Hipponensem" (28. VIII. 1986), 2: AAS 79 (1987), p. 146.

7 «En este ir y venir, ondulante y pendular de la historia de los hombres y las ideas, estamos, otra vez, viviendo tiempos Agustinianos. Tiempos de decadencias morales y desencantamientos políticos. De materialismos maniqueos y humanismos pelagianos. De sectarismos donatistas y escepticismos académicos. Tiempos de muchas palabras y poco silencio. De muchos ruidos y poca interioridad. De muchas instancias confusas y pocas referencias trascendentes.» P. RuBIO, «San Agustín: una conciencia crítica para hoy», en AA.VV., San Agustín y la Liheración. Reflexiones desde Latinoamérica, Lima 1986, p. 219. 
wara, «Agustín es, en la historia del espíritu, el pensador que capta el instante y lo refleja espontáneamente. Toda especulación intuitiva y rítmica le reconoce como antecesor y maestro. Es también y, por lo mismo, el pensador de las oposiciones vivientes, de las actitudes contrapuestas de defensa y ataque» ${ }^{8}$.

Este estudio quiere acercarse al término «regula fidei» en la teología de San Agustín para entender mejor la problemática que una cierta normatividad de fe presenta al hombre de hoy. Por tanto, un contacto con los escritos de Agustín para analizar el contexto en el cual fue utilizado el término «regula fidei», así como su frecuencia en los mismos, es indispensable para una mejor comprensión del término ${ }^{9}$, y poder presentar sistemáticamente, hasta donde sea posible, el concepto del término, exponiéndolo en tres niveles diversos, para tener una visión global e integral.

Sin duda alguna que un acercamiento al término «regula fidei», presenta ciertos límites y nuevas areas de investigación. De hecho, nosotros no entramos al análisis de términos sinónimos tales como "doctrina apostolica", "catholica fidei", "regula apostolica", "regula ecclesiastica", "regula veritatis", regula pietatis"..., cuyo estudio requiere una labor similar a la presente. No obstante, creemos que, el aproximarnos al término «regula fidei» como tal, nos ofrece una síntesis conceptual de lo que éste significó para este Padre y Doctor en estudio, pues a decir de él mismo en su obra De Trinitate: «Fija la mirada de mi atención en esta regla de fe, con la que te he buscado según mis fuerzas, y en la medida que Tú me hiciste capaz, pues anhelé ver con mi inteligencia lo que creía mi fe, por la cual mucho disputé y en ello me afané» ${ }^{10}$.

Las implicaciones teológicas de nuestros resultados nos permiten afirmar que la respuesta agustiniana emerge con toda su actualidad, ya que ofrece un basto margen de actuación en la exégesis bíblica, el dogma y la pastoral. La «regula fidei», según Agustín, se proyecta en el progreso doctrinal, que corresponde a la elaboración dogmática u ortodoxia, y la vivencia de fe como compromiso cristiano u ortopraxis. San Agustín se mueve en la comprensión del contenido de la fe, en donde su método teológico supone la adhesión plena a la autoridad de la fe (una en su origen: Cristo), que se

8 E. Przywara, San Agustín. Perfil humano y religioso, Madrid 1984(2), p. 15.

9 Ciertamente no basta saber cuál es el concepto que Agustín tiene sobre el término «regula», sino que debemos acercarnos al término técnico. Sobre el concepto «regula» véase: L. Cilleruelo, «El concepto de "Regula" en S. Agustín», en La Ciudad de Dios 181 (1968), 816-824

10 De Trin. 15,51: CCL 50A, 534. 
manifiesta a través de la Escritura, la Tradición y la Iglesia; al ardiente deseo de comprender la propia fe; el sentido del misterio del hombre y la búsqueda de Dios; la seguridad convencida de que la doctrina cristiana viene de Dios y tiene por lo mismo su originalidad que no sólo hay que conservar en su integridad, sino que debe servir también como medida para juzgar filosofías conformes o contrarias a ella, conservando siempre la unidad en la caridad ${ }^{11}$.

Sea patente nuestro agradecimiento al "Augustinus-Lexikon" dirigido por Cornelio Mayer, OSA., por las facilidades prestadas en la elaboración de este mínimo estudio.

\section{EL TÉRMINO «REGULA FIDEI» EN LOS ESCRITOS DE S. AGUSTÍN ${ }^{12}$.}

\subsection{Escritos apologéticos.}

En De Civitate Dei (413-426) encontramos el término «regula fidei» en cuatro ocasiones: dos veces en el libro XI y dos en el XIV. En todas ellas, Agustín utiliza el término «regula fidei» en relación al sentido que las Sagradas Escrituras presentan, explicando «la obscuridad de la sentencia del autor» sagrado, y que, por tanto, «pueden dar lugar a muchas opiniones» ${ }^{13}$. Sin embargo, la «regula fidei» no nos permite apartarnos de su significado propio ${ }^{14}$, pues éste «es bien conocido a los fieles a través de otros pasajes de las santas Escrituras que tienen la misma autoridad» ${ }^{15}$. Entonces el lector puede elegir una u otra opinión, de acuerdo a la «regula fidei» ${ }^{i 6}$.

\subsection{Escritos dogmáticos.}

Dentro del grupo de los escritos así llamados dogmáticos, producción que abarca del 388 al 425, el término «regula fidei» aparece en diez ocasiones.

11 Ioannes Paulus II, «Aug. Hip.» 4: ÁAS 79 (1987), p. 167-168.

12 Nuestro análisis de los textos por grupos sigue el criterio de los géneros literarios propuestos por A. TRAPE, «San Agustín», en Patrología. La edad de oro de la literatura patrística latina, vol. III, Madrid 1986, 422-481.

13 «Quia non elucet cur vel unde sit dictum, multos sensus peperit eius obscuritas, cum divinarum scripturarum quisque tractator secundum fidei regulam id conatur exponere.» De civ Dei 15,7: CCL 48,460.

14 «...quod hic scriptum est (...); sed aliud dicat aliquid, quod a fidei regula non sit alienum.» Idem 15,26: CCL 48,494.

15 «etiamsi aliud hoc loco sensit forte qui scripsit, non est inutiliter obscuritas huius pertractata sententiae, quia, etsi voluntatem auctoris libri huius indagare nequivimus, a regula tamen fidei, quae per alias eiusdem auctoritatis sacras litteras satis fidelibus nota est, non aberravimus.» Idem 11,33: CCL 48, 353.

16 «Proinde ut volet quisque accipiat, quod ita profundum est, ut ad exercitationem legentium a fidei regula non abhorrentes plures possit generare sententias». Idem 11,32: CCL 48,352 . 
Mientras que en el libro De diversis quaestionibus (388-396) «regula fidei» se identifica con la Escritura ${ }^{17}$ como interpretación correcta del pasaje de Jn 24,28ss., en la mayoría de los textos ${ }^{18}$ se trata de un sinónimo del «Symbolum» o la profesión de fe, llamada también Credo. En cambio, tanto en el Enchiridion (421) 8 como en el De Trinitate (399-420) 8,1, el término está usado en sentido general y amplio de doctrina ${ }^{19}$.

Particularmente, en De Trin. 15,49 Agustín nos ofrece una connotación en relación al proceso discursivo del pensamiento o reflexión filosófico-teológica, ya que en este caso, la «regula fidei» adiestra («exerceat») y dirige («regente») la mente humana ${ }^{20}$.

\subsection{Escritos morales.}

En el libro De bono viduitatis, escrito en el 414, San Agustín expone la doctrina paulina sobre la bondad del estado de viudez. De hecho, dice Agustín: «No voy, pues, a enseñarte otra cosa sino a exponerte las palabras del Doctor apostólico y a discutirlas según me lo permita el Señor» ${ }^{21}$, pues «sancta enim scriptura nostrae doctrinae regulam figit, ne audeamus "sapere plus quam oportet sapere", sed sapiamus, ut ipse ait, "ad temperantiam, sicut unicuique Deus partitus est mensuram fidei" ${ }^{22}$.

Aquí, el término «regula fidei» es simplemente la doctrina que podemos obtener de las Escrituras para conocer lo que conviene saber con templanza,

17. «Regula auten catholicae fidei sic se habet, ut cum aliqua in scriptura dicuntur de Filio quod minor sit Patre, secundum susceptionem hominis intellegantur, cum vero ea dicuntur quibus demonstratur aequalis, secundum id quod Deus est accipiantur». De Div. quaest. oct. 69,1: CCL 44A, 184.

18 Ençh. 56: CCL 46,80; De fide et op. 7, 11 (aparece 2 veces): CSEL 41,47; De Trin. 2,17: CCL 50,102; 15,51: CCL 50A, 534; De octo Dulc. quaest. 3,4: CCL 44A,277.

19 «In epistula quippe ad Hebraeos, qua teste usi sunt illustres catholicae fidei ac regulae defensores, fides dicta est "convictio rerum quae non videntur"» [Ench. 8: PL 40,259]. «Nunc itaque in quantum ipse adiuvat creator mire misericors, attendamus haec quae modo interiore quam superiora tractavimus, cum sint eadem, servata illa regula ut quod intellectui nostro nondum eluxerit a firmitate fidei non dimittatur.» [De Trin. 8,1: CCL 50,269].

20 «Quantum vero attinet ad illam summam, ineffabilem, incorporalem immutabilemque naturam per intellegentiam utcumque cernendam, nusquam se melius regente dumtaxat fidei regula acies humanae mentis exerceat quam in eo quod ipse homo in sua natura melius ceteris animalibus, melius etiam ceteris animae suae partibus habet, quod est ipsa mens cui quidam rerum invisibilium tributus est visus, et cui tamquam in loco superiore atque interiore honorabiliter praesidenti iudicanda omnia nuntiant ẹtiam corporis sensus, et qua non est superior cui subdita regenda est nisi Deus.» De Trin. 15,49: CCL 50A,531.

21 De bono vid. 2: CSEL 41,306. El subrayado es nuestro para indicar la carga léxica que precedè al término «regula fidei».

22 Idem 2: CSEL 41,306. 
según la «mensuram fidei» o la «regula doctrinae». Ambos términos expresan la correspondencia de la actitud existencial (virtud) con la doctrina, los cuales se integran como norma de fe.

\subsection{Escritos exegéticos. .}

El término «regula fidei» viene usado diez veces en este grupo de textos. Debemos notar inmediatamente que, en una de ellas, Agustín citando Rom 12, 1.6-16 pone en letra de Pablo el término «regula fidei»: «Et totus fere ipsius exhortationis locus temperatum habet elocutionis genus; ubi illa pulchriora sunt, in quibus propria propriis tamquam debita reddita decenter excurrunt, sicut est: "habentes dona diversa secundum gratiam, quae data est nobis, sive prophetiam secundum regulam fidei...» ${ }^{23}$. Es claro que en este caso, «regula fidei» viene citada para afirmar la medida o proporción de la fe, refiriéndose al estilo y armonía de la carta paulina o «apostolica verba» como la denomina aquí.

En los demás textos Agustín indica diferentes conceptos. Nuestro análisis nos lleva a individuar tres:

a. Podríamos decir que la «regula fidei» es la enseñanza apostólica ${ }^{24}$ transmitida por los evangelios ${ }^{25} \mathrm{o}$ la sagrada Escritura ${ }^{26}$. Esta es fuente de vida para la fe, por tanto, puede y debe ser considerada como una autoridad

23 De doc. christ. 4,40: CCL 32.146. Agustín leía así el texto: «Habentes autem donationes secundum gratiam, quae data est nobis, differentes; sive prophetiam secundum rationem fidei.» [Vetus Latina, Rom XII,6]. Al reportarlo nos da «regulam fidei» en lugar de «rationem fidei» como sinónimos. En realidad, «ratio» significa en cualquier manera «mensura, modus, proportio, ratio, norma, regula, analogia...».

24 «...differentia ista vel gentium vel conditionis vel sexus iam quidem ablata est ab unitate fidei, sed manet in conversatione mortali eiusque ordinem in huius vitae itinere servandum esse et apostoli praecipiunt, qui regulas saluberrimas tradunt, (...). Alia sunt enim quae servamus in unitate fidei sine illa distantia, et alia in ordine vitae huius tamquam in via, ne nomen Dei et doctrina blasphemetur.» Expo. ep. ad Gal. 28: CSEL 84,93.

25 «Ac ne putaretur, quod attinet ad percipiendum et praedicandum Evangelium, interesse aliquid utrum illi annuntient, qui eumdem Dominum hic in carne apparentem discipulatu famulante secuti sunt, an ii qui e illis fideliter comperta crediderunt; divina providentia procuratum est per Spiritum sanctum ut quibusdam etiam ex illis qui primos Apostolos sequebantur, non solum annuntiandi verum etiam scribendi Evangelium tribueretur auctoritas: hi sunt Marcus et Lucas. Ceteri autem homines, qui de Domini vel de Apostolorum actibus aliqua scribere conati vel ausi sunt, non tales suis temporibus extiterunt, ut eis fidem haberet ecclesia adque in auctoritatem canonicam sanctorum librorum eorum scripta reciperet, nec solum quia illi non tales erant, quibus narrantibus credi oporteret, sed etiam quia scriptis suis quaedam fallaciter indiderunt, quae catholica adque apostolica regula fidei et sana doctrina condemnat.» De conse. Ev. 1,2: CSEL 43,2-3.

26 «...sicut omnia miracula, quae in scripturis reperiuntur, significantia quod pertineat ad regulam 'fidei». Quaest. in Hept. 5,29: CCL 33,292. 
segura, en la interpretación de la misma Escritura ${ }^{27}$, clarificando otros pasajes ${ }^{28}$, sean ambiguos u oscuros. En este sentido viene a ser un criterio hermenéutico de la exégesis bíblica correcta.

b. «Regula fidei» es al mismo tiempo autoridad de la Iglesia en cuanto que expone correctamente la doctrina ${ }^{29}$ que debe ser creída y aceptada por todos ${ }^{30}$.

c. El término «regula fidei» indica la tradición ${ }^{31}$ canónica -«canonem in auctoritatis arce»-, o no canónica -«ecclesiasticae litterae-, con la cual, por su autoridad propia, la Iglesia enseña la verdad de la fe.

\subsection{Escritos polémicos.}

\subsubsection{Contra los Maniqueos.}

En la disputa maniquea el término «regula fidei» viene reclamado una vez, discutiendo con Fausto (397-398). «Regula fidei» ${ }^{32}$ viene relacionada al

27 «Porro autem, si non solum non inpediunt, verum etiam solidius adserunt divini eloquii narrationem haec etiam corporaliter intellecta, nemo erit, ut opinor, tam infideliter pertinax, qui cum ea secundum regulam fidei exposita proprie viderit malit in pristina remanere sententia, si forte illi visa fuerant, nonnisi figurate posse accipi.» De Gen. ad lit. VIII 1,4: CSEL 28,232.

28 «Sed cum verba propia faciunt ambiguam Scripturam, primo videndum est ne male distinxerimus, aut pronuntiaverimus. Cum ergo adhibita intentio incertum esse perviderit, quomodo distinguendum aut quomodo pronuntiandum sit, consulat regulam fidei, quam de scripturarum planioribus locis et ecclesiae auctoritate percepit, de qua satis egimus, cum de rebus in libro primo loqueremur. Quod si ambae vel etiam omnes, si plures fuerint partes, ambiguetatem secundum fidem sonuerit, textus ipse sermonis a praecedentibus et consequentibus partibus...» De doc. christ. 3,2: CCL 32,78.

29. Explicando la doctrina trinitaria, no como lo explican los herejes, sino como debe ser entendida: «Sed hoc regula fidei refellendum est, qua nobis de trinitatis aequalitate praescribitur, ut dicamus: "et Deus erat Verbum", deinde subiungamus: "Hoc erat in principio apud Deum"(Io I,1-2).» De doc. christ. 3,3: CCL 32,78. Un texto iluminador al respecto: «Quae cum ita se habeant, iam facile est etiam illud videre, fieri posse ut quisque in ecclesiae societate doctrinam integram veramque assequatur, et omnia secundum catholicae fidei regulam edisserat...» Quaest. Ev. 2,40: CCL 44B,100.

30 «Non enim magnum est tunc eum [al demonio] dinoscere, cum ad aliqua peruenerit vel perduxerit, quae sunt contra bonos mores vel regulam fidei: tunc enim a multis discernitur» De Gen. ad lit. XII 14,28: CSEL 28,398.

31 «Quoniam si acutum et fervens adsit ingenium, facilius adhaeret eloquentia legentibus et audientibus eloquentes quam eloquentiae praecepta sectantibus nec desunt ecclesiasticae litterae, etiam praeter canonem in auctoritatis arce salubriter conlocatum, quas legendo homo capax, etsi id non agat, sed tantummodo rebus, quae ibi dicuntur, dum in his versatur, imbuitur accedente vel maxime exercitatione sive scribendi sive dictandi, postremo etiam dicendi, quae secundum pietatis ac fidei regulam sentit.» De doc. christ. 4,4: CCL 32,118. Cf. De consensu Ev. 1,2 (n. 14).

32 «Et si non utrumque ex unius Apostoli litteris proferretur, sed unum eorum Paulus dixisset, alterum Petrus, aut Isaias, aut alius quisquam Apostolorum, sive Prophetarum; quia 
canon del N.T. y al Symbolum. Apelando a la «canonica auctoritas» del Corpus Paulinum, el cual no puede contradecir lo que creemos por el resto de la Escritura y que forma nuestro Credo o Symbolum.

\subsubsection{Contra los Donatistas.}

En la obra De Baptismo (400), Agustín cita tres veces el término «regula fidei». Los cristianos, que viven de acuerdo con la «regula fidei», conservan siempre «la obediencia a la autoridad de la Iglesia» ${ }^{33}$ pues ella expone con verdad la recta doctrina y las rectas costumbres, es decir, «el buen efecto de la caridad» ${ }^{34}$. Por tanto, se tiene la garantía de celebrar los sacramentos y la oración. Los herejes, en cambio, no se someten a la recta observancia de la caridad $^{35}$, engañados por una doctrina viciosa.

\subsubsection{Contra los Pelagianos.}

En la polémica anti-pelagiana el término «regula fidei» viene usado once veces. Es interesante notar que Juliano, obispo pelagiano, en dos ocasiones cita la «regula fidei» expresada por Agustín. Juliano pregunta a San Agustín sobre la «regula fidei» ${ }^{36}$ respecto al matrimonio y al bautismo. Agustín responde tomando como norma de fe Rom 4,23-25. Dice: «Bene contra vos

ita sibi omnia in canonica auctoritate concordant... non liceret de alterutro dubitare. Proinde quia ex apostoli Pauli canonicis, id est vere Pauli epistulis, utrumque profertur et non possumus dicere aut mendosum esse codicem -omnes enim Latini emendati sic habent- aut interpretem errasse -omnes enim Graeci emendati sic habent- restat, ut tu non intellegas, a me autem ratio flagitetur, quomodo neutrum ab altero dissonet, sed in eadem sanae fidei regula utrumque concordet.» Contra Faust. manich. 11,6: CSEL 25,322.

33 «Quidam vero adhuc carnales et animales provectus suos instanter exercent et, ut cibo spiritalium fiant idonei, sanctorum mysteriorum lacte nutriuntur, ea quae in pravis moribus populari etiam iudicio manifesta sunt in dei timore devitant et, ut minus minusque rebus terrenis et temporalibus delectentur, vigilantissime satagunt, regulam fidei diligenter inquisitam firmissime tenent et, si quid ab ea deviant, cito auctoritate catholica corriguntur, quamvis in eius verbis pro sensu carnali variis adhuc phantasmatum» De Bapt. V 27,38: CSEL 51,295 .

34 «Quia plerumque precis vitium superat precantis adfectus et quia certa illa verba evangelica, sine quibus non potest baptismus consecrari, tantum valent, ut per illa sic evacuentur quaecumque in prece vitiosa contra regulam fidei dicuntur, quemadmodum daemonium Christi nomine excluditur (cf. Mc 16,17). Nam utique haereticus, si adferat precem vitiosam, nec bonum habet caritatis adfectum, quo possit illa imperitia superari, et ideo similis est ei quicumque in ipsa catholica invidus et maliuolus, quales illic arguit Cyprianus, adferat etiam, ut fieri solet, aliquam precem in qua loquatur contra regulam fidei.» Idem VI 25,47: CSEL 51,323.

35 Idem.

36 Dice Juliano: «"Cum ergo ille adhuc in praeputio testis sit fidei pronuntiatus et ob eius stipendium dilatationem fuerit seminis consecutus, qua, inquit, regula tu, Iudaee, non putas ad consortium iustitiae pertinere gentiles, qui fidem Abrahae, paria de Dei virtutibus credendo, restituunt?"» Contra Iul. op. imperf. 2,155: CSEL 85,278. 
loqueris: quia utique si de Dei virtutibus credunt, non sicut vos confidunt in virtute sua, ut justificentur, id est, ut justi fiant; sed in illius, qui justicat impium» ${ }^{37}$. En el otro texto del Contra Iulianum operus imperfectum (430) Juliano cita el fragmento de la obra agustiniana, escrita en el 419-420, De nuptiis et concupiscentia $2,4^{38}$.

Contra la concepción pelagiana del bautismo de los niños y el matrimonio cristiano, Agustín apela a la «regula fidei». Esta es la fe universal de la Iglesia ${ }^{39}$, «que es unánimamente en todos el sentir de la Iglesia católica, y que se remonta a la fe transmitida desde los tiempos antiguos y sólidamente establecida con voz, de algún modo clara, y que se revuelve muy enérgicamente contra los herejes» ${ }^{40}$. Agustín así lo demuestra llamando en causa testimonios válidos de la Tradición de los Padres, «episcopis Christi» ${ }^{41}$, como Ambrosio ${ }^{42}$, Cipriano o los Concilios ${ }^{43}$. La doctrina ortodoxa demuestra que

37. Idem.

38 «Etiam hic ea praetermisit, in quibus aures catholicas timuit; nam ut ad haec verba veniretur, supra dictum erat a nobis: hoc ergo quia dicimus, quod antiquissima atque firmissima catholicae fidei regula continetur, isti novelli et perversi dogmatis assertores, qui nihil peccati esse in parvulis dicunt quod lavacro regenerationis abluatur, tamquam damnemus nuptias et tamquam opus Dei, hoc est hominem, qui ex illis nascitur, opus diaboli esse dicamus, infideliter vel imperite calumniantur.» Contra Iul. op. imperf. 1,22: CSEL 85,19 (cf. De nup. et concup. 2,4: CSEL 42,256).

39 «Quapropter quisquis (...) in qua [fides] dubitari vel errari salva fide potest, sed in ipsa regula fidei, qua christiani sumus». De grat. Christi et pec. or. II 29,34: CSEL 42, 193.

40 «[regula fidei] quia cuncta ecclesiae catholicae pectora convenit fidemque ipsam antiquitus traditam atque fundatam clara quodam modo voce compellat et adversus eos vehementissime permovet quod diximus...» De nup. et concup. 2,4: CSEL 42,256.

41 «Alia sunt in quibus inter se aliquando etiam doctissimi atque optimi regulae catholicae defensores, salva fidei compage non consonant, et alius alio melius aliquid dicit et verius.» Contra Iul. I 6,22: PL 44,655. Concretamente Agustín se refiere a Inocencio, Cipriano, Basilio, Gregorio, Hilario, Ambrosio, etc., cuando dice «doctissimi et optimi defensores».

42 «Audi quid inde in alio loco expressius dicat sanctus Ambrosius in Expositione evangelii secundum Lucam [In Lc 7,14 = PL 15,1825], cum diversis modis, ab una tamen regula fidei non abhorrentibus, tractaret illum locum, ubi Dominus ait, in una domo dividi tres adversus duos, et duos adversus tres (cf. Lc XII,52).» Idem II 5,10: PL 44,680.

43 «Vides quanta fiducia ex antiqua et indubitata regula fidei vir [Cyprianus] tantus ista loquatur?» De pec. mer. III,5,11: CSEL 60,137. Agustín se refiere concretamente a lo que Cipriano define como verdadero en Ep. 64 ad Fidum II 1-2;V 2 (= CSEL 3,2, 717;721), es decir, que «nadie tiene que tener obstáculo para recibir la gracia por la ley ya establecida..., sino que todo hombre sin inconveniente alguno, debe ser admitido a la gracia de Cristo», por tanto también los niños pueden ser admitidos al bautismo. En este mismo texto, Agustín reclama lo definido por el Concilio de Cartago del 251, con estas palabras: «Qui haec documenta certissima ideo protulit, ut illud quod erat incertum, unde consuluerat ille cui rescribit, et unde concilii decretum constitutum esse commemorat...». De hecho, el Concilio había declarado que: «...a baptismo adque a gratia Dẹi, qui omnibus misericors et benignus et pius est, neminem per nos debere prohiberi. Quod cum circa universos observandum sit adque retinendum.» CSEL 3,2,721. 
los herejes viven una heteropraxis. En otras palabras, no se puede vivir rectamente si no se ha creído rectamente. En estos términos, la ortodoxia se transforma en ortopraxis eclesial respecto al matrimonio y al bautismo ${ }^{44}$, ya que esta es la «antigua e indudable», «cristiana y católica», «antiquísima y firmísima» «regula fidei» que salva siempre la unidad en la fe ${ }^{45}$.

\subsubsection{Contra los Arrianos.}

En abierta polémica con el obispo arriano Maximino, alrededor del 427428, el término «regula fidei» aparece dos veces. Para Agustín la «regula fidei» es ante todo la «recta» vía interpretativa del Evangelio ${ }^{46}$, la cual al exponer el contenido de la fe, debe ser enseñada «íntegramente» y no sólo una parte de ella como lo hacían los arrianos, quienes al interpretar la Escritura sólo hacían una lectura fundamentalista, contradiciendo así la verdad de los testimonios apostólicos, y atentando contra la integridad del mismo Evangelio ${ }^{47}$.

\subsubsection{Contra los Marcionitas.}

En su posición antimarcionita, Agustín reclama en dos ocasiones la «regula fidei» en su obra Contra adversarium legis et prophetarum (420).

La doctrina cristiana contenida en la Sagrada Escritura, no puede oponerse a lo que se ha enseñado, ni puede contradecirse a sí misma, ya que los dos Testamentos están íntimamente unidos: uno es figura del otro y se explican mutuamente. Esto es la «regula fidei», la cual nos permite confirmar el testimonio que de la Ley y los Profetas de las «venerables Escrituras» nos da el N.T., sobre todo en las Cartas Paulinas ${ }^{48}$. A esta «sana regu-

44. Cf. De pec. mer. II 27,43 [=CSEL 60,115]; De grat. Christi et pec. or. II 29,34 [=CSEL 42,193\}; De nup. et concup. I 1,1 [=CSEL 42,212]; II 2,4 [=CESEL 42,256]; Contra . duas ep. pelag. IV 3,3 [=CESEL 60,523].

45 «Ac per hoc qui cum iudicio legunt et secundum regulam fidei adprobanda adprobant et inprobant inprobanda, etiamsi commendant memoriae quae inprobanda dicuntur, nulla venenata sententiarum pravitate laeduntur.» De anima et eius orig. II 17,23: CSEL 60,358. Esta idea viene también expresada en la fidelidad a la doctrina: «...si a Christianae fidei regula nolumus aberrare.» De pec. mer. II 27,43: CSEL 60,115.

46 «Sic teneres rectam regulam fidei, ut non contradiceres veritati; nec per talia testimonia oppugnares Evangelium, sed doceres.» Contra Max. arr. II 14,8: PL 42,775.

47 Un ejemplo lo da el mismo Agustín: «"Ascendo ad Deum meum et ad Deum vestrum" (Io. XX,17), Dominum propter formam servi dixisse, quam suscepit, asseris, ut puto, ut dicis: si ipse humilians se in corpore dum esset humano, quamvis devicta morte triumphato diabolo post resurrectionem suam, isto utitur sermone, dicens: "Ascendo ad Patrem meum et ad Patrem vestrum": ubi iam humilitas carnis necessaria non erat, ut dicis, propter Iudaeos: sed integra regula fidei tradebatur.» Collatio cum Max. arr. episc. 16: PL 42,733.

48 «Nos autem audiamus, et intelligamus duo testamenta in duobus filiis Abrahae, duabusque mulieribus eius commixtione fetatis: sicut duos in carne una, Christum et Ecclesiam, istis nolentibus, sine ulla obscoenitate cognoscimus: sicut mediatorem Dei et hominum hominem Christum Iesum (I Tim II,5), (...): atque in omnibus sanctis Scripturis, secundum sanae 
la» ${ }^{49}$ se opone la «regula falsa» ${ }^{50}$ de los marcionitas («blasphematores et adversi»), quienes desprecian las «Santas Escrituras». Con esta falsa regla de fe nada se puede enseñar ni aprender, vanificando al Espíritu Santo. La «regula fidei» es garantía de una recta exégesis bíblica.

\subsection{Epistolario.}

\subsubsection{Del 396 al 411 .}

En este período encontramos una vez el término «regula fidei» en la Ep. 102,37: explicando algunos pasajes del libro de Jonás, «regula fidei» es la interpretación propia sometida al criterio revelado en el Evangelio ${ }^{51}$.

\subsubsection{Del 411 al 430 .}

Por cuatro veces la correspondencia agustiniana nos presenta el término «regula fidei», que viene usado para resaltar, ante todo, su función en la manera de interpretar la Escritura, ya que siendo «concordes con la recta fe» se asegura la unidad de la Iglesia en cuanto a la doctrina y a las costumbres ${ }^{52}$, pues ésta es la norma de la fe ${ }^{53}$ católica. Así lo demuestran las inter-

fidei regulam figurate dictum vel factum si quid exponitur, de quibuslibet rebus et verbis quae sacris paginis continentur, expositio illa ducatur, non aspernanter, sed sapienter audiamus; et relinquamus istum inania garrientem, et nesciendo quid loquatur, quadam, si dici potest, imperita peritia de figurarum qualitate tractantem.» Contra advers. leg. et proph. II 9,34: CCL 49,119-120.

49 «Sive aliquid aliud, quod hic salva fidei regula intelligi potest: Deum tamen verum et summum et bonum fecisse cuncta quae cernimus, et quae meliora non cernimus, quamvis modus quo ea fecerit comprehendi humana mente non possit, dubitare fas non est. Sed cum istis inductis blasphematoribus Litterarum sacrarum non ea rationum subtilitate agendum est, quia ista quaerenda sunt et inter pacificos Dei filios disputanda.» Idem I 10,13: CCL 49,45. A estos mismos marcionitas les llama «adversus Libros legis et Prophetarum» (I $11,14)$.

50 «Convincitur enim regula falsa, sed sua; nec sapientis ac docti, sed stulti, sicut ipse est, atque ineruditi manu, suo tamen gladio jugulatur». Idem II 9,34: CCL 49,119.

51 «Liceat sane cuilibet quamlibet aliter dum tamen secundum regulam fidei cetera omnia, quae de Iona propheta mysteriis operta sunt, aperire; illud plane, quod in ventre ceti triduo fuit, fas non est aliter intellegere, quam ab ipso caelesti magistro in Evangelio commemoravimus revelatum.» Ep. 102,37: CSEL 34,577.

52 «Unde ut non recedant, regulam fidei pusillis magnisque communem in ecclesia perseveranter tenent et, in quod pervenerunt, in eo ambulant et, donec eis Deus revelet, si quid aliter sapiunt, cogitationes suas carnales non dogmatizant, quia non obdurant contentiosis defensionibus inmanendo, sed quodam modo ambulando, id est proficiendo desudant intellegentiae perspicuitatem impetrantes per fidei pietatem.» Ep. 187,29: CSEL 57,107.

53 «Si autem in his verbis Apostoli nullus alius sensus potuerit reperiri et hoc eum intellegi voluisse claruerit, quod videntur verba ipsa clamare..., huic sententiae (cf, II Cor V,4) procul dubio conveniet, quod in regula fidei confitemur...» Ep. 193,11: CSEL 57,174. 
pretaciones de los Padres ${ }^{54}$. Viene expresada en la imagen del camino: «en el camino al que hemos llegado, en ese caminemos hasta que el Señor nos revele si algo menos bueno sentimos», pues hemos llegado a algunas verdades que «sabemos con certidumbre que pertenecen a la fe verdadera y católica» ${ }^{55}$.

\subsubsection{De fecha incierta.}

La Ep 265 expresa una vez el término «regula fidei». Aquí «regula fidei» es sinónimo de la fe de la Iglesia Católica, la cual es norma de fe en cuanto que es la doctrina de Cristo y de los apóstoles ${ }^{56}$.

\subsection{Tratados.}

\subsubsection{Tratado sobre el Evangelio de San Juan (415).}

El término «regula fidei» viene presentado seis veces. La «regula fidei» nos permite interpretar la Escritura ${ }^{57}$, dándonos la seguridad de la fe recta y de la doctrina ortodoxa ${ }^{58}$ que de ella se puede sacar. Pero la misma Escritura es «regula fidei». Es decir, la fidelidad ${ }^{59}$ al texto nos permite afirmar que creemos la sana y católica recta norma de fe ${ }^{60}$, puesto que «las herejías y dog-

54 «Sed sive hoc in istis apostolicis verbis etiam ille senserit evangelicus disputator [Ambrosius, Sermo 140,26,62-64] sive aliud aliquid fortasse congruentius, vides tamen etiam hoc, ni fallor a regula fidei non abhorrere.» Ep. 147,34: CSEL 44, 308.

55 Ep. 217,15: CSEL 57,414. cf. Ep. 187,29: CSEL 57,107.

56 «Unde quaere diligenter, ne forte alicuius alterius erroris sit et Novatianum se esse confingat vel putet aut, si et hoc Novatiani dicunt, nescio; illud tamen scio, quoniam, quisquis hoc dicitur [que los apóstoles cambiaron la penitencia por el bautismo], a regula fidei catholicae et a doctrina Christi et apostolorum prorsus alienus est.» Ep. 265,6: CSEL 57,644.

57 «Sed qui supplet, quod minus erat addit, non quod inerat tollit; qui autem praetergreditur fidei regulam, non accedit in via, sed recedit de via» In ev. Io. tract. 98,7: CCL 36,581.

58 «Si quid ergo intellexeris quod non sit contra regulam catholicae fidei, ad quam, velut viam quae te ducat ad patriam, pervenisti, et sic intellexeris, ut inde dubitare omnino non debeas, adde aedificium; noli tamen relinquere fundamentum.» Idem 98,7: CCL 36,580.

59 «Quasi vero quisquam regulam fidei fideliter intuens, Filium Dei negaturus est praedestinatum, qui eum negare hominem non potest.» Idem 105,8: PL 35,1907. Esta posición se contrapone a quienes falsean el mensaje: «Non autem solum vaniloquos et mentis seductores fabulosa et falsa garrientes, et in eis vanitatibus velut altam scientiam promittentes contra regulam fidei, quam catholicam suscepistis, cavere debetis... tamquam pestem insidiosiorem ceteris fugite.» Idem 98,7: CCL 36,580.

60 «Itaque, carissimi, valde caute haec audire debemus, ad quae capienda parvuli sumus; et corde pio et cum tremore, sicut scriptum est, hanc tenentes regulam sanitatis, ut quod secundum fidei qua imbuti sumus, intellegere valuerimus, tamquam de cibo gaudeamus; quod autem secundum sanam fidei regulam intellegere nondum potuerimus, dubitationem auferamus, intellegentiam differamus; hoc est, ut etiam si quid sit nescimus, bonum tamen et verum esse minime dubitemus.» Idem 18,1: CCL 36,180. 
mas de perversión, que enredan las almas y las arrojan al abismo, no se originan sino de la mala inteligencia de las buenas Escrituras y de que lo que se ha entendido mal se afirma con tenacidad y audacia» ${ }^{61}$. Existe, pues, una intercambiabilidad entre «regula fidei» $\mathrm{y}$ «Scriptura», de tal manera que sólo así podemos decir que la «regula fidei» es la «sana doctrina» ${ }^{62}$.

\subsubsection{Comentarios a los Salmos (393-422).}

En las Enarrationes in Psalmis el término «regula fidei» aparece cuatro veces. Siempre expresa el modo correcto de interpretar los salmos. En efecto, la «regula fidei» permite un margen de interpretación; marca ella misma un límite ${ }^{63}$ en la predicación, sobre el cual no se puede sobrepasar la interpretación ${ }^{64}$. No obstante, cualquier sentido que surja en el contacto con el texto bíblico, sobre todo cuando es oscuro ${ }^{65}$, debe sujetarse a la «regula fidei» ${ }^{66}$, que en este caso podría entrar en el margen de variedad de la interpretación o de los sentidos ${ }^{67}$.

\subsubsection{Homilias.}

En la abundante predicación de Agustín el término «regula fidei» viene presentado ocho veces. Este indica:

a. Generalmente indica el «Symbolum fidei» o un artículo del mismo Credo. Así: Sermo 59,1; 186,2; 215,9; 362,7. Explícitamente, el Símbolo es la «regula fidei» ${ }^{68}$ compendiada en pocas palabras: «breve en el número de

61 In ev. Io. tract. 18,1: CCL 36,180.

62 «Eo modo enim significare (...) secundum regulam fidei sanamque doctrinam...» Idem 106,2: CCL 36,609.

63 «Quamvis enim ea potius crederent quae ipsi faciebant, ut morerentur, ea tamen praedicabant, quae si alli credentes facerent, salvarentur; non enim aliud annuntiabant praeter regulam fidei.» En. in Ps. 115,1: CCL 40,1652.

64 «...quaelibet ergo harum sententia placeat, quo iste versus referatur, regulam fidei non excedit.» En. in Ps. 9,6: CCL 38,61.

65 «quia sic se habet obscuritas Scripturarum: difficile est ut unum pariant intellectum.» En. in Ps 74,12: CCL 39,1033.

66 «Quicumque tamen intellectus exierit, opus est ut regulae fidei congruat; nec maioribus invidemus, nec parvuli desperamus.» Idem.

67 «Possunt quidem verba ista sic intellegi, non praeter regulam fidei, sed est hic alius sensus quem mihi fateor plus placere.» En. in Ps. 118,12,2: CCL 40,1701.

68 «Symbolum est ergo breviter complexa regula fidei, ut mentem instruat, nec oneret memoriam; paucis verbis dicatur, unde multum adquiratur.» Sermo Guelf 1,2: PLS 2,537. Sobre el texto véase el aparato crítico de Misc. Aug. I,441-450. Nuestro texto citado aparece también en el Sermo 213,1: PL 38,1060. 
palabras, grande por el peso de sus artículos» ${ }^{69}$. «Todo lo que profesamos en ella lo profesamos desde la verdad y en la verdad en que vivimos, nos movemos y existimos» ${ }^{70}$, por eso es «norma que se refiere al misterio de la fe» ${ }^{71}, y$ se confiesa al ser bautizado ${ }^{72}$.

b. El término se refiere a la interpretación de las Escrituras, en donde la «regula fidei» es criterio exegético. En este sentido es sinónimo de la «regula veritatis» ${ }^{73}$.

c. Significa la tradición de la Iglesia. «Regula fidei» viene calificada como antigua («antiquam»), la cual no se puede contradecir con nuevas disputas («novis disputationibus») ${ }^{74}$.

\subsubsection{Exposición del Símbolo a los catecúmenos.}

En el breve tratado De Symbolo, sermo ad Catechumenos, de fecha incierta, Agustín identifica explícitamente el «Symbolum» con la «regula fidei» ${ }^{75}$. Ahora bien, «Symbolum» indica claramente la verdad de la Sagrada Escritura. De hecho, en el mismo texto Agustín sostiene que el símbolo (= «regula fidei») está contenido en las Escrituras divinas en forma dispersa, pues de «ellas ha sido recogido y redactado en un texto para que todos los hombres puedan profesarlo y creerlo» ${ }^{76}$.

69 «Ideo prius Symbolum didicistis, ubi est regula fidei vestrae brevis et grandis: brevis, numero verborum; grandis pondere sententiarum.» Sermo 59,1: PL 38,400.

70 «Et quidquid ibi [regula fidei] confitemur, ex veritate et in veritate confitemur, in qua vivimus et movemur et sumus.» Sermo 362,7: PL 39,1614.

71 «Videtis certe, charissimi, etiam in ipsis sancti symboli verbis, quomodo conclusioni omnium regularum, quae ad sacramentum fidei pertinent, quasi supplementum quoddam additum, ut diceretur, per sanctam ecclesiam.» Sermo 215,9: PL 38,1076.

72 «Carnis autem resurrectionem habemus in regula fidei, et eam confitentes baptizamur.» Sermo 362,7: 39,1614.

73 «Nam quando nos inquirentes Scripturas sentimus aliquid, quod scriptor forte non sensit; non tamen hoc sentire debemus, quod abhorret a regula fidei, a regula veritatis.» Sermo 7, 3: PL 38,63-64.

74 «Quare contradicis? Quare novis disputationibus antiquam fidei regulam frangere conaris?» Sermo 174,9: PL 38,945. Aquí se refiere a los pelagianos: cf. n. 32. 46,185 .

75 «Accipite, filii, regulam fidei, quod Symbolum dicitur.» De Symb. ad cath. 1,1: CCL

76 «Hoc est enim Symbolum, quod recensuri estis et reddituri. Ista verba quae audistis per divinas Scripturas sparsa sunt: sed inde collecta et ad unum redacta...ut omnis homo possit dicere, possit tenere quod credit» Idem, 1,1 = CCL 46,185. 


\subsection{Escritos autobiográficos.}

\subsubsection{Confesiones (397-400).}

En las Confessiones Agustín usa una vez el término «regula fidei», con el cual indica simplemente la doctrina cristiana a la que él se ha convertido ${ }^{77}$, revelado así a Mónica ${ }^{78}$.

\subsubsection{Retractaciones (426-427).}

En la obra de las Retractationes Agustín dice que escribió el libro De agone christiano (cerca del 396), en donde expuso la «regula fidei» respecto a la doctrina (explica el símbolo de la fe y nombra los errores o herejías que hay que evitar), y respecto a la praxis de vida (ascético-moral). En este sentido, el término «regula fidei» viene a indicar la norma de vida cristiana en lo que se ha de creer y vivir ${ }^{79}$.

\subsection{Conclusión del capítulo.}

El término «regula fidei» se puede individuar en la llamada «Opera omnia Sancti Augustini» al menos 71 veces. De su análisis podemos deducir una conclusión provisoria, es decir, la «regula fidei» no es un término unívoco. Por el contrario, constatamos que presenta diversas connotaciones en cuanto a su valor contenido ${ }^{80}$.

$\mathrm{Su}$ riqueza lexicográfica no sólo se demuestra en los diferentes sentidos -expresados en diferentes contextos y situaciones concretas-, sino que presenta una compleja versatilidad terminológica, dependiendo del énfasis retórico del autor ${ }^{81}$.

77 «Convertisti enim me ad te, ut nec uxorem quaererem nec aliquam spem saeculi huius stans in ea regula fidei, in qua me ante tot annos ei revelaveras, et "convertisti luctum eius in gaudium" (Ps 29,12) multo uberius, quam voluerat, et multo carius atque castius, quam de nepotibus carnis meae requirebat.» Confes. VIII 12,30: CCL 27,132.

$78 \mathrm{Se}$ refiere concretamente a la «regla de madera» soñada por Mónica nueve años antes del 386: Confes. III 11,19.

79 «Liber de agone Christiano fratribus in eloquio Latino ineruditis humili sermone conscriptus est fidei regulam continens et praecepta vivendi.» Retract. 2,3: CCL 57,91.

80 Esta riqueza del contenido o concepto será el objeto de nuestro siguiente capítulo, presentado sistemáticamente.

81 Filológicamente, el campo semántico del término «regula fidei» viene precisado con los siguientes calificativos latinos: catholica, christiana, apostolica, ecclesiastica, canonica, sana, salva, recta, indubitabile, vera, certa, firma, solida, optima, salubris, una, complexa, antiqua e integra; en ocasiones los adjetivos vienen en grado superlativo: antiquissima, firmissima. El término atrae los verbos: tradere, accipere, dicere, habere, consulare, percipere, vedere, udire, praecipere, regere, dirigere, sentire, loqui, legere, exponere, continere, intelligere, cernere, repperi, adprobare, defendere, credere; o bien los verbos negativos como: abhorrere, contendere, dubitare, errare, inprobare, damnare, deficere, devitare, contradicere, disputare. Se presenta en sentido absoluto (caso nominativo), o bien, relacionado con preposición (contra, secundum, propter, a, ab, in) o conjunción (ac, autem, et). 
Podemos constatar que es un término que viene relacionado con los términos Scriptura, verba apostolica, litterae sacrae, canon scripturae, Symbolum, doctrina, heresia, habitudines y mores.

\section{EL CONCEPTO DEL TÉRMINO «REGULA FIDEI» EN EL PENSAMIENTO TEOLÓgICO DE SAN AgUSTÍN.}

\subsection{El término «regula fidei» a nivel exegético.}

\subsubsection{La Sagrada Escritura.}

La premisa de la cual parte Agustín está precisamente en que todo el contenido de la fe y los preceptos de la vida cristiana están contenidos en la Escritura: «In his enim quae aperte in scripturis posita sunt, inveniuntur illa omnia quae continent fidem moresque vivendi» ${ }^{82}$. De este modo, la misma Escritura es una norma objetiva de fe.

En efecto, S. Agustín argumenta señalándole al texto mismo un valor categórico que debe aceptarse ${ }^{83}$. Por lo tanto, el valor que tienen las Escrituras consiste en la autoridad ${ }^{84}$ que ellas mismas presentan, en cuanto que fue-

82 De doc. christ. 2,14: CCL 32,41.

83 Muchos son los textos que se pueden citar al respecto, sin embargo, sólo citamos aquí las expresiones referidas a la Escritura que están relacionadas directamente al término «regula fidei»: 1. «De eo quod scriptum est (I Cor XV,28)... regula autem catholicae fidei sic se habet, ut cum aliqua in scriptura dicuntur...» De div. quaest. oct. 69,1: CCL 44A,184; 2. «et quia certa illa verba evangelica... in prece vitiosa contra regulam fidei dicuntur [haereses]» De Bapt. 6,47: CSEL 51,323; 3. «etsi voluntatem auctoris libri huius indagare nequivimus, a regula tamen fidei, quae per alias eiusdem auctoritatis sacras litteras satis fidelibus nota est, non aberravimus» De civ. Dei 11,33: CCL 48, 353; 4. «cum divinarum scripturarum quisque tractator secundum fidei regulam id conatur exponere» Idem 15,7: CCL 48,460; 5. «quod hic scriptum est...; sed aliud dicat aliquid, quod a fidei regula non sit alienum» Idem 15,26: CCL 48,494 ; 6. «sicut omnia miracula, quae in scripturis reperiuntur, significantia quod pertineat ad regulam fidei» Quaest. in Hept. 5,29: CCL 33,292; 7. «atque in omnibus sanctis scripturis, secundum sanae fidei regulam figurate dictum vel factum si quid exponitur, de quibuslibet rebus et verbis quae sacris paginis continentur, expositio illa ducatur, non aspernanter, sed sapienter audiamus» Contra advers. leg. et proph. II 9,34: CCL 49,119-120; 8. «sancta enim scriptura nostrae doctrinae regulam figit...» De bono vid. 2: CSEL 41,306; 9. «si his atque huiusmodi testimonis [evangelistarum]...: sic teneres rectam regulam fidei, ut non contradiceres veritati; nec per talia testimonia oppugnares evangelium sed doceres» Contra Max. arr. episc. II 14,8: PL 42,775; 10. «sed sive hoc in istis apostolicis verbis... a regula fidei non abhorrere» Ep. 147,34: CSEL 44,308.

84 Continua a ser actual el estudio realizado sobre la autoridad de las Escrituras en cuanto a su carácter divino, del cual la Iglesia se nutre continuamente: Ch. DESPINEY, Le chemin de la foi après Saint Augustin, Senonis 1930 (esp. 369-372). También puede verse: B. de MARgerIE, Introduzione alla storia dell'esegesi. v. III: Sant'Agostino, Roma 1986, p. 15-32; A. Pollastri/F. Cocchini, Bibbia e storia nel cristianesimo latino, Roma 1988, p. 23-33; C. BASEvi, San Agustín. La interpretación del Nuevo Testamento, Pamplona 1977, p. 148-179, y en relación con la fe: p. 193-199. 
ron inspiradas por el Espíritu Santo. Explícitamente, Agustín expresa esta objetividad normativa de la fe, ya que «no habrías otorgado -dice en las Confesiones-, a esa Escritura una tan señalada autoridad en todo el mundo, si no hubieras querido que por medio de ella se creyese en ti y por medio de ella se te buscase» ${ }^{85}$.

\subsubsection{El canon bíblico.}

En modo particular Agustín se refiere al canon bíblico o a la Escritura canónica ${ }^{86}$. En este sentido, la escritura es presentada y explicada por la Iglesia. En efecto, sólo la escritura es «canonica auctoritas», pero tanto la definición del canon como su exacta interpretación son propias de la Iglesia en su totalidad. «Cuando San Agustín afirma que si se quieren evitar las herejías que nacen del interpretar mal las Escrituras, y de las mismas herejías, con temeridad y audacia, su errónea interpretación, y si se quiere comprender alguna cosa de la fe recibida y disfrutarla como se disfruta de un alimento sano, se requiere tener la regla de la salud, la sana regla de la fe (In Io. tr. 18,1) ${ }^{87}$.

De hecho, Agustín conoció un elenco de libros canónicos ${ }^{88}$, a los cuales reclama como «regula fidei» por su autoridad, así por ejemplo los Evangelios ${ }^{89}$, el «Corpus Paulinum» ${ }^{90}$, la carta a los Hebreos ${ }^{91}$, etc.. A esta «regula fidei»se refiere cuando habla del canon en general ${ }^{92}$. En este sentido, es también «regula veritatis»: «nam quando nos inquirentes scripturas sentimus aliquid quod scriptor forte non sensit; non tamen hoc sentire debemus quod abhorret a regula fidei, a regula veritatis» ${ }^{93}$.

- 85 Confes. VI 5,8: CCL 27,78.

86 «Credit [civitas Dei] Scripturis sanctis et veteribus et novis quas canonicas appellamus, unde fides ipsa concepta est.» De civ. Dei 19,18: CCL 48,686.

87 G. Favara, La necessità della Chiesa secondo S. Agostino, Arcireale 1949, p. 17. Cf. G. MASCHIO, «L'argomentazione patristica di S. Agostino nella prima fase della controversia pelagiana (412-418), en Augustinianum 26 (1986), 459-479, p. 467. Nosotros nos hemos referido a este texto citado por Favara en 2.7.1.

88 Cf. De doc. christ. 2, 12-13.

89 De consensu Ev. 1,2; Ep. 102,37; Ep. 147,34; In Io. ev. tr. 36,2.

90 Contra Faust. manich. 11,6.

91 Ench. 8.

92 Sermo 186,2.

93 Sermo 7,3: PL 38,63-64. Ciertamente en este texto parecería que se trata de dos cosas distintas: Símbolo y Escritura. Sin embargo, creemos que se trata del mismo sentido, es decir, una puede precisar la Escritura y otra se refiere a su interpretación. El problema se amplía ante otros textos en donde aparece el término «r. veritatiș»: Contra Iul. 1,16; De haeresibus; De anima et eius orig. 2,15; De doc. christ. 1,8; Contra Faust. manich. 11,2. En todos ellos o se refiere a la interpretación de la Escritura o a la doctrina. El problema viene tratado indirectamente en la nota 20 del tomo. VII de Obras completas de San Agustín [BAC, Madrid 1981(4), p. 750], en donde se opta por la interpretación de las Escrituras, pero identificando ambos términos. En cambio, en G. MARTIL, La Tradición en San Agustín a través de la 
Precisamente, en el libro De consensu Evangelistarum se expone la «regula fidei» en estrecha relación con el canon bíblico con estos términos: «ut eis [homines] fidem haberet ecclesia adque in auctoritatem canonicam sanctorum librorum eorum scripta reciperet..., quae catholica adque apostolica regula fidei» $(1,2){ }^{94}$.

De este texto tenemos dos características fundamentales tanto de la «regula fidei» como del canon de la Escritura, es decir, la catolicidad ${ }^{95}$ y la apostolicidad ${ }^{96}$. Por catolicidad se entiende aquello que en todas partes lo verdadero se tiene como tal y se predica así como se cree ${ }^{97}$, porque siempre se ha tenido así ${ }^{98}$; de tal manera que el mismo Agustín afirma que él no creería en el Evangelio si la Iglesia no lo presentara para ser creído ${ }^{99}$. Apostolicidad, en cambio, expresa el concepto de continuidad y transmisión del mensaje de Cristo, anunciado por los Apóstoles a través de la Iglesia en el tiempo y en el espacio, ya que, como lo dice poéticamente San Agustín, «la santa Iglesia apostólica se propagó y creció merced a estos agricultores,

controversia pelagiana, Madrid 1943, a p. 166 y luego a p. 170 concluye que son términos «con parecido significado». Otra óptica la encontramos en LoF, L.J. van der, «Regula Apostolica in the Liber de unico baptismo», en Augustiniana 21 (1971), 449-456, en donde se comparan los términos «r. apostolica» $\mathrm{y}$ «r. veritatis»: «The two rules lean on one another. But the regula apostolica is a part of the truth which the regula veritatis contains. It is going too far to suggest that Augustine would identify the two rules» (p. 449); sin embargo, ambas tienen la misma autoridad, porque están sostenidas por la «auctoritas ecclesiae»: «In Augustine there is no opposition between apostolic tradition and apostolic authority on the one hand, and Tradition and Holy Scripture on the other hand» (p. 452).

94 CSEL 43,2-3. En el contexto Agustín trata de explicar la canonicidad y autoridad de los Evangelios de Marcos y Lucas, quienes «primos Apostolos sequebantur, non solum annuntiandi verum etiam scribendi Evangelium tribueretur auctoritas» de acuerdo a la «sana doctrina» $y$ «per Spiritum Sanctum».

95 Sobre la catolicidad en Agustín véase el insuperable estudio realizado por P. BATIFFol, Le catholicisme de saint Augustin, Paris 1929(5), esp. p. 21-45. Así mismo, Th. CAMElot, "Autorité de l'Écriture, autorité de l'Église. A propos d'un texte de saint Augustin», en Bibliothèque Thomiste 37 (1967), 127-133.

96 Cf. P. ZMIRE, «Recherches sur la collégialité épiscopale dans l'Eglise d'Afrique», en Recherches Augustiniennes 7 (1971), 3-72; L.J. VAN DER LoF, «Regula Apostolica...» art. cit.

97 «Catholica autem fides ex utroque verum tenens quod tenet, et praedicans quod credit, et Deum Christum intellexit, et hominem credidit; utrumque enim scriptum est, et utrumque verum est.» In Io. ev. tract. 36,2: CCL 36,324.

98 «Hoc Ecclesia semper habuit, semper tenuit: hoc a maiorum fide percepit; hoc usque in finem perseveranter custodit» Sermo 176,2,2: PL 42,176.

99 «Si invenires aliquem, qui Evangelio nondum credit, quid faceres dicenti tibi: Non credo? Ego vero Evangelio non crederem, nisi me catholicae Ecclesiae commoveret auctoritas.» Contra ep. manich. 5,6: CSEL 25,197. 
regantes, arquitectos, pastores y proveedores» ${ }^{100}$ que han sucedido a los Apóstoles ${ }^{101}$.

Podemos afirmar que, la relación íntima entre el canon escriturístico y la «regula fidei» viene presentada como garantía de la verdad. Así, «nuestra fe, es decir, la fe verdadera, la fe recta, la fe católica se profesa; fe que no se funda en opiniones o conjeturas, sino en el testimonio de la lectura escuchada; fe que no duda ante la temeridad de los herejes, sino que se cimienta en la verdad de los apóstoles, pues así lo sabemos y así lo creemos» ${ }^{102}$.

\subsubsection{La «regula fidei» en la exégesis agustiniana.}

Debemos partir de los dos aspectos anteriormente expuestos, es decir, que para Agustín existe una relación casi idéntica entre «regula fidei» y «Scriptura divina», y que la interpretación de la Escritura solo es posible bajo la autoridad de la Iglesia.

Ahora bien, dentro del proceso exegético agustiniano, la «regula fidei» viene a jugar un papel importante. De hecho, «tanto en la interpretación alegórica como en la literal el exégeta debe atenerse a la "regula fidei". Precisamente a la luz de esta "regula fidei" y de los pasajes más claros de la Escritura ha de juzgarse si una proposición es o no aceptable. La Iglesia es la regla suprema de la interpretación bíblica. Si el estudioso, después de un examen diligente, queda incierto acerca de un pasaje bíblico, debe recurrir a la "regula fidei" que se identifica con los términos propuestos por el magisterio de la Iglesia» ${ }^{103}$.

100. Talibus [Patres] post Apostolos sancta Ecclesia plantatoribus, rigatoribus, aedificatoribus, pastoribus, nutritoribus crevit» Contra Iul. 2,37: PL 44,700; cf. Sermo 52,2: «fides enim nostra...sed apostolica veritate fundata».

101 «Videtis certe multos praecisos a radice christianae societatis, quae per sedes Apostolorum et successiones episcoporum certa per orbem propagatione diffunditur, de sola figura originis, sub christiano nomine, quasi arescentia sarmenta gloriari, quas haereses et schismata nominamus» Ep. 232,3: CSEL 57,513.

102 «Fides enim nostra, id est, fides vera, fides recta, fides catholica, non opinione praesumptionis, sed testimonio lectionis collecta, nec haeretica temeritate incerta, sed apostolica veritate fundata, hoc insinuat; hoc novimus, hoc credimus.» Sermo 52,2,2: PL 38,355. Cf. De doc. christ. 2,12: «Tenebit igitur hunc modum in Scripturis canonicis, ut eas quae ab omnibus accipiuntur Ecclesiis catholicis, praeponat eis quas quaedam non accipiunt: in eis vero quae non accipiuntur ab omnibus, praeponat eas quas plures gravioresque accipiunt, eis quas pauciores minoresque auctoritatis Ecclesiae tenent» (CCL 32,39).

103 A. MANRIQUE, «Interpretación y utilización de la Biblia en San Agustín», en La Ciudad de Dios 182 (1969), 153-174, p. 167. 
Un acercamiento detallado al término «regula fidei» en la exégesis agustiniana nos permite apreciar una perspectiva más amplia y dinámica al interno de la hermenéutica ${ }^{104}$, y de la misma exégesis bíblica ${ }^{105}$.

En el De doc. christ. Agustín expone las normas de la exégesis, para que el exégeta encuentre el sentido auténtico del texto, es decir, lo que el autor sagrado quiso decir. Para ello, se deben distinguir el sentido literal o figurativo del texto ${ }^{106}$.

Todo lo que en las sagradas Escrituras se prefigura en dichos o hechos, «cosas o palabras que las sagradas páginas contienen» deben exponerse con armonía de acuerdo a los tipos o figuras, de acuerdo a su cualidad o materia de que traten. Es decir, las correctas palabras o hechos figurados expuestos según la «regula fidei» ${ }^{107}$. La razón que justifica este principio se basa en que «todos los milagros que en las Escrituras se encuentran corresponden a un significado en la regla de la fe» ${ }^{108}$. De ahí que este método sea denominado «analogia fidei» o alegórico.

104 Cf. G. Ripant, Agostino teorico dell'interpretazione, Brescia 1980. El texto es un estudio sobre la hermenéutica de Agustín presentada en el libro De doctrina christiana. Para nuestra investigación interesa sobre todo el cap. 1 (p. 13-27). Al respecto concluye: «C'è sempre un originario legame tra l'interpretazione nel'senso tecnico di essegesi testuale e la comprensione nel senso ampio di intelligenza dei segni. Tale legame è dovuto al costituirsi stesso dell'esercizio ermeneutico, che originariamente si inscrive nell'ambito religioso e giuridico.» (p. 27).

105 Entre la abundante bibliografía sobre el tema, se puede consultar: M. PONTET, L'exégèse de St. Augustin prédicateur, Paris 1946; B. de MARgerie, Introduzione alla..., obra cit.; C. BASAve, San Agustín...., obra cit.; B. PreTe, "I principi esegetici di S. Agostino», en Sapienza 8 (1955), 552-594.

106 Sobre el sentido literal véase: M. Aviles, «Prontuario agustiniano de ideas exegéticas», en Augustinus 20 (1975), 297-338. Respecto al sentido alegórico: M. MARIN, «Allegoria in Agostino", en AA.VV. La Terminologia esegetica nell'antichità, Bari 1987, 135-161. Para una visión de conjunto puede verse las colaboraciones en Lateranum 48 (1982): P. GRECH, «I principi ermeneutici di S. Agostino: una valutazione», 209-223; A. TRAPÉ, «S. Agostino esegeta: teoria e prassi», 224-237.

107 «atque in omnibus sanctis scripturis, secundum sanae fidei regulam figurate dictum vel factum si quid exponitur, de quibuslibet rebus et verbis quae sacris paginis continentur, expositio illa ducatur, non aspernanter, sed sapienter audiamus; et relinquamus istum inania garrientem, et nesciendo quid loquatur, quadam, si dici potest, imperita peritia de figurarum qualitate tractantem» Contra advers. leg. et proph. II 9,34: CCL 49,119-120. Ejemplos de la aplicación que Agustín hace en plena correspondencia con la «regula fidei» lo encontramos en este mismo texto, en De Gen. ad lit. VIII 1,4; en De civ. Dei 11,33 y 15,26,2; en Enarrat. in Ps. 9;6. La estructura que nos presenta sería generalmente así: a) figura del A.T. b) aplicación a la realidad Cristo-Iglesia c) apelo a la «regula fidei» d) exhortación para aceptar el sentido expuesto.

108 «sicut omnia miracula, quae in scripturis reperiuntur, significantia quod pertineat ad regulam fidei» Quaest. in Hept. 5,29: CCL 33,292. 
Por otra parte, el sentido que el autor sagrado ha dado al texto o a la sentencia que ha escrito, no puede contradecir lo que ya hemos entendido claramente y con seguridad ${ }^{109}$, y por tanto forma parte de la fe profesada. En este sentido la «regula fidei» debe ser el criterio de armonía y desarrollo de la exégesis, pues el sentido literal -«quod videntur verba ipsa clamare»-, es el sentido obvio del texto que no puede sobrepasar aquello de lo que estamos seguros, más bien debe armonizarse con ese depósito de verdades, cuales norma de interpretación ${ }^{110}$.

Sin embargo, no siempre se puede llegar al sentido figurado o literal, dada la obscuridad del texto. En caso de ambigüedad Agustín propone una crítica textual ${ }^{111}$ :

1. Cuando las palabras propias hacen ambigua la santa Escritura lo primero que se ha de ver es si puntuamos mal ${ }^{112}$, o bien, ir a la sentencia menos oscura $^{113}$.

2. Si prestada la atención necesaria todavía aparece incierto cómo haya de puntuarse o pronunciarse, se debe consultar la «regula fidei» que se adquirió de otros lugares más claros de la Escritura o según la autoridad de la Iglesia ${ }^{114}$.

3. Pero si ambos sentidos o todos, en el caso de que hubieren muchos, resultan ambiguos sin salirnos de la regla de la fe, nos resta consultar el texto

109 Cf. De Bapt. 6,47.

$110 \ll \mathrm{Si}$ autem in his verbis apostoli nullus alius sensus potuerit reperiri et hoc eum intellegi voluisse claruerit, quod videntur verba ipsa clamare, id est quod futuri sint in fine saeculi et in adventu Domini, qui non expolientur corpore, sed superinduantur inmortalitate, "ut absorbeatur mortale a vita" (II Cor. V,4), huic sententiae procul dubio conveniet, quod in regula fidei confitemur» Ep. 193,11: CSEL 57,174.

111 «Sed cum verba propia faciunt ambiguam Scripturam, primo videndum est ne male distinxerimus, aut pronuntiaverimus. Cum ergo adhibita intentio incertum esse peruiderit, quomodo distinguendum aut quomodo pronuntiandum sit, consulat regulam fidei, quam de scripturarum planioribus locis et ecclesiae auctoritate percepit, de qua satis egimus, cum de rebus in primo loqueremur. Quod si ambae vel etiam omnes, si plures fuerint partes, ambiguitatem secundum fidem sonuerit, textus ipse sermonis a praecedentibus et consequentibus partibus...» De doc. christ. 3,2: CSEL 32,78.

112 Agustín propone un ejemplo con la puntuación que hacen los herejes (arrianos) al pasaje Jn 1,1-2, dándole un sentido distinto al verdadero, por el cual pretenden no confesar la divinidad del Verbo: «sed hoc regula fidei refellendum est, qua nobis de trinitatis aequalitate praescribitur, ut dicamus: "et Deus erat Verbum", deinde subiungamus: "hoc erat in principio apud Deum".» De doc. christ. 3,3: CCL 32,78.

113 «Proinde quia ex apostoli Pauli canonicis, id est vere Pauli epistulis, utrumque profertur et non possumus dicere aut mendosum esse codicem -omnes enim Latini emendati sic habent- aut interpretem errasse -omnes enim Graeci emendati sic habent- restat, ut tu non intellegas, a me autem ratio flagitetur, quomodo neutrum ab altero dissonet, sed in eadem sanąe fidei regula utrumque concordet» Contra Faust. manich. 11,6: CSEL 25, 321-322.

114 Cf. De civ. Dei 11,33; 15,7,1; Enarrat. in Ps. 9,6. 
de lo que antecede y sigue al pasaje en donde se encuentra la ambigüedad, a fin que veamos a qué sentido de los muchos que se ofrecen favorezca y con cuál se armoniza mejor, con él mismo o con otros textos afines, que a su vez se constituyen en norma de fe para el pasaje en estudio ${ }^{115}$.

Así, la «regula fidei» nos permite encontrar el sentido auténtico del autor. No obstante que dicha ambigüedad u obscuridad nos lleve a muchos sentidos verdaderos concordes y en armonía con la «regula fidei» ${ }^{116}$, o en caso de no alcanzar el sentido auténtico, sin embargo no la contradice ${ }^{117}$. En este sentido, podemos afirmar que la «regula fidei» garantiza la unidad interpretativa del texto bíblico ${ }^{118}$.

Contemporáneamente, la «regula fidei» nos impide por una parte, la mala interpretación que se puede hacer del texto ${ }^{119}$, y por otra, el ser ligeros ante la Palabra de Dios ${ }^{120}$.

Finalmente, el exégeta debe confrontar su interpretación ante la-interpretación autorizada de la Iglesia o de otros estudiosos (como los Padres), la cual puede ser considerada como norma exegética ${ }^{121}$.

\subsubsection{Crítica al uso de la «regula fidei» en la exégesis.}

Este tipo de interpretación en base a la «regula fidei» puede ser considerado como una "exégesis dogmática" como lo sugiere Studer ${ }^{122}$, o bien, una "interpretación eclesiástica de las Escrituras" según M. Grant ${ }^{123}$. Sin embargo, aunque si ambas expresiones manifiestan un aspecto de la exégesis agustiniana, debemos sostener que no son precisas. En efecto, no siempre, como

115. Cf. De Gen. ad lit. VIII, 1,4; De fide et op. 7,11; Sermo 7,3.

116 Así: De civ. dei 11,32; 15,7,1; 15,26,2; Ep. 102,37; Ep. 215,15; Enarrat in Ps. 74,12 y $118,12,2$.

117 Sermo 7,3; Enarrat. in Ps. 118,12,2.

118. In Io. ev. ev. tract. $98,7$.

119 Idem 18,1 .

120 Sermo 186,2 .

121 Enarrat. in Ps. 74,12; Ep. 147,34; cf. Contra Iul. II 10,34.

122 «Le verità fondamentali provenienti dalla stessa Bibbia e raggruppate di solito nello schema della fede battesimale nel Padre, Figlio, Spirito Santo, costituiscono la base di quell'esegesi che potrebbe chiamảrsi dogmatica. Si trata di un determinato sistema teologico che si tenta di illustrare mediante la lettura della Scritura. Tuttavia in questo tipo di esegesi non si sviluppano necessariamente tutte le singole verità della "regula fidei", ma nella maggior parte dei casi si parte dalle sole verità che vengono contestate dagli avversari o che sono discusse all'interno della comunità.» B. STUDER, La Riflessione Teologica nella Chiesa Imperiale (sec. IV e V), Roma 1989, p. 153.

123 «Nous n'étudierons pas ici le De doctrina christiana en lui-même, mais comme un exemple de l'interprétation ecclésistique de l'Écriture. Augustin n'est pas un traditionaliste pur et simple, mais il se réfère toujours à l'autorité de la règle de foi.» R.M. GRANT, L'interprétation de la Bible des origines chrétiennes à nos jours, Paris 1967, p. 94. 
hemos visto, el término «regula fidei» se refiere a las verdades explícitas de la fe o «dogmas», pues en ocasiones el término designa el mismo texto escriturístico. Por otra parte, aunque si la interpretación siempre se circunscribe al ámbito de la «regula fidei», y por tanto bajo la dirección de la Iglesia, no obstante la misma «regula fidei» permite una amplitud de los límites exegéticos con la variedad de los sentidos que, en tanto no se opongan a la Escritura o al Símbolo de fe, nos lleva al sentido del texto escrito y por tanto a la intención del autor sagrado.

Pero debemos afirmar que «el sentido espiritual que se respira en toda la elaboración hermenéutica de S. Agustín, lejos de comportar peligro alguno para la integridad y ortodoxia de su doctrina, sirve para enriquecerla y comunicarla de un modo más adecuado y eficaz a los hombres de su tiempo» ${ }^{124}$, ya que «un tratado completo de exégesis agustiniana debe partir más bien de su práctica exegética y no de sus principios hermenéuticos. Pues lo que lo salvó de los errores en los cuales cayeron sus adversarios fue la constante apelación a la "regula fidei" que lo hace, si no siempre un óptimo filólogo, uno de los más grandes teólogos bíblicos en la historia de la literatura cristiana» ${ }^{125}$.

\subsection{El término «regula fidei» a nivel dogmático.}

\subsubsection{El Símbolo de la fe.}

Formalmente la «regula fidei» se expresa en las verdades de la fe codificadas en el «Symbolum fidei». En este sentido la «regula fidei» es el mismo Credo de la Iglesia tomado íntegramente ${ }^{126}$, o bien puede referirse a cada artículo que lo forma ${ }^{127}$.

El Símbolo se constituye en la regla de fe para el creyente ya que sus verdades están contenidas en la Sagrada Escritura; precisamente de ella ha sido recogido y resumido en un texto breve para que todos puedan recitarlo, retenerlo y creerlo ${ }^{128}$. Por su parte, el Símbolo debe confesarse en el momento del bautismo (redditio symboli) una vez que se ha recibido (traditio sym-

124 A. MANRIQUE, «Interpretación...» art. cit., p. 168.

125 P. GRECH, «I principi...» art. cit., p. 134.

126 De Symb. ad cath. 1,1; Sermones 213,2 (Guelf 1,2 ); 59,1; 362,7.

127 De Trin. 15,50; Ench. 56,15; Sermones 186,2;215,9; $362,7$.

128 «Accipite, filii, regulam fidei, quod Symbolum dicitur... Hoc est enim Symbolum, quod recensuri estis et reddituri. Ista verba quae audistis, per divinas Scripturas sparsa sunt: sed inde collecta et ad unum redacta... ut omnis homo possit dicere, possit tenere quod credit.» De Symb. ad cath. 1,1: CCL 46,185. 
boli) del obispo a nombre de la comunidad ${ }^{129}$. Así, esta regla de fe tiene ciertas características:

- es común a los pequeños y a los grandes ${ }^{130}$;

- es breve y grande al mismo tiempo: breve en el número de palabras, grande por el peso de sus artículos ${ }^{131}$;

- está compendiada en pocas palabras porque debe ser aprendida de memoria ${ }^{132}$;

- en variedad de formas contiene las verdades de fe por la cual somos cristianos ${ }^{133}$

- presenta una jerarquía en las verdades ${ }^{134}$.

Esta «regula fidei» es una norma de salvación ${ }^{135}$, porque ésta «es la fe y la verdad de la Iglesia católica», por tanto, «quien os anunciare, dice Agustín, otra cosa distinta de la que habéis recibido, sea anatema» ${ }^{136}$. Por eso el

129 «et eam [regula fidei] confitentes baptizamur» Sermo 362, 7: PL 39,1614. Un testimonio al respecto lo narra Agustín en boca de Simpliciano, hablando de la conversión de Mario Victorino: «cuando llegó por fin el momento de la profesión de fe, que es una fórmula precisa, aprendida y recitada de memoria, desde un lugar elevado, en presencia del pueblo fiel (...). Mas él prefirió emitir la profesión de la salud en presencia de la asamblea santa» (Conf. VII 2,5). Cf. también Sermones 212, 213, 214, 215 y 216, De Symb. ad cat., etc. Sobre la «redditio» y «traditio» del Símbolo a los catecúmenos véase V. Grossi, La Liturgia battesimale in S. Agostino, Roma 1970; F. van der MeER, San Agustín pastor de almas, Barcelona 1965, p. 459-464.

130 Ep. 187,29 .

131 Sermo 59,1; cf. De Symb. ad cath. 1,1.

132 Cf. Sermones 212,1;213,2 (Guelf 1,2);214,1.2; De Sýmb. ad cath. 1,1.

133. «Nam in sanctis scripturis et in sermonibus ecclesiasticis ea multis modis posita soletis audire» Sermo 214,1: PL 38,1066. Cf. Sermo 362,7; De gratia Christi et pec. orig. II 29,34.. Esta característica nos permite sugerir la forma del «Symbolum» o «regula fidei» usado por Agustín y en la Iglesia africana del s. V. Agustín nos presenta al menos cuatro versiones que corresponden sustancialmente al Símbolo de la forma Milanesa e Hiponense: I. Tomada del De fide et operibus. II. Tomada de los Sermones 212, 213 (Guelf 1) y 214. III. Tomada del Sermo 215. IV. Tomada del Sermo de Symbolo ad catechumenos. A propósito véase DS 14 con estudio crítico, así como el Apéndice C (Symbola) del CCL 50A, p. 558-563. Al respecto existe una abundante bibliografía: C. EICHENSEER, Das Symbolum Apostolicum beim heiligen Augustinus, St. Ottilien 1960; C. BASEVI, «Introducción al libro La fe y el símbolo de los Apóstoles» en Obras completas de San Agustín tomo 39, Madrid 1988, 363-383; B. STUDER, «Augustin et la Foi de Nicée» en Recherches Augustiniennes 19 (1984), 133-154; P. ZMIRE, "Recherches sur la collégialité épiscopale dans l'Eglise d'Afrique» en Recherches Augustiniennes 7 (1971), 3-72; Ch. MuniER, «Vers une édition nouvelle des Concilies Africains (345-525)» en Revue des Études Augustiniennes 18 (1972), 249-259.

134 «Sed collecta et in ordinem certum redacta atque constricta tradenda sunt vobis, ut fides vestra aedificetur» Sermo 214,1: PL 38,1066. Cf. Ench. 56,15; Sermo 215,9.

135 «Fides ergo haec et salutis est regula...» Sermo 215,2: PL 38,1072.

136 «Credentes ergo divinam trinitatem et trinam unitatem, cavete, dilectissimi, ne quis vos ab ecclesiae catholicae fide atque veritate seducat. Qui enim vobis aliter vobis evangelizaverit, praeterquam quod accepistis, anathema sit. Apostolum, non me audite, qui ait: "Sed et si nos, aut angelus de caelo aliter vobis evangelizaverit, praeterquam quod accepistis, anathema sit" (Gal. I,8)» Sermo 215,8: PL 38,1076. 
cristiano «debe escribirla en su corazón para repetirla todos los días antes de dormir, al salir de casa y al empezar las tareas» ${ }^{137}$. Sólo así la «regula fidei» nos instruye con palabras para progresar en las costumbres ${ }^{138}$, pues caminar bajo su sombra es estar en la «firmissima regula fidei» de la doctrina católica.

\subsubsection{La Tradición.}

Agustín afirma que «todo lo que observamos por tradición, aunque no se halle escrito; todo lo que observa la Iglesia en todo el orbe, se sobreentinde que se guarda por recomendación de los Apóstoles o de los Concilios plenarios, cuya autoridad es indiscutible en la Iglesia. Lo mismo diremos 'de cualquier otra práctica semejante que se observe en toda la Iglesia universal» ${ }^{139}$. Este carácter genético con la doctrina de los Apóstoles, transmite también una autoridad normativa para la fe ${ }^{140}$. De hecho, a esto se refiere cuando dice «la antigua e indudable» regla de la fe ${ }^{141}$. Así, San Agustín recurre a la autoridad de algunos obispos anteriores a él, «ilustres defensores de la doctrina católica» ${ }^{142}$.

Estos «doctísimos e invictos defensores de la fe católica» aunque pueden discrepar en algunos puntos, sin embargo salvan siempre la unidad en la fe, precisamente por la «regula fidei» común a todos ellos ${ }^{143}$.

La llamada a una tradición eclesiástica o a los «episcopi Christi» como «regula fidei», viene subrayada en cuanto a la interpretación y uso de las sagradas Escrituras ${ }^{144}$, la praxis litúrgica ${ }^{145} \mathrm{o}$ la disciplina ecclesiástica ${ }^{146}$,

137 De Symb. ad cath. 1,1: CCL 46,185.

138 «Nos instruimus sermonibus, vos proficite moribus, spargimus sermonem verbi, fructum reddite fidei. Omnes secundum vocationem qua vocati sumus a Domino, in eius via semitaque curramus; nullus retro respiciat.» Sermo 216,1: PL 38,1076.

139 «Illa autem quae non scripta, sed tradita custodimus, quae quidem toto terrarum orbe servantur, datur intelligi vel ab ipsiis Apostolis, vel plenariis conciliis, quorum est in Ecclesia saluberrima auctoritas, commendata atque statuta reteneri... et si quid aliud tale occurrit quod servatur ab universa, quacumque se diffundit, Ecclesia» Ep. 54,1: CSEL 34,159-160. Cf. Sermo 176,2,2; De Bapt. contra Donat. 4,24.

140 «...nec desunt ecclesiasticae litterae. etiam praeter canonem in auctoritatis arce salubriter conlocatum... quae secundum pietatis ac fidei regulam sentit» De doc. christ. 4,4: CCL 32,118 .

141 De pec. m. et rem. III 5,11.

142 «illustres catholicae fidei ac regulae defensores» Ench. 8: CCL 46,52.

143 Contra Iul. I 6,22. Aquí se refiere a los obispos Inocencio, Basilio, Gregorio, Hilario, Ambrosio, etc.

144 Contra Iul. II 5,10; Ench. 8; Ep. 147,34; Enarrat. in Ps. 74,12.

145 De Bapt. VI 25,47.

146 De pec. mer. et rem. III 5,11 . 
sobre todo en oposición a la interpretación, praxis y disciplinas heterodoxas de los herejes ${ }^{147}$.

En realidad, los Padres son la voz de la Iglesia pues «después de los Apóstoles, la Iglesia ha crecido con estos agricultores, regantes, constructores, pastores y proveedores» ${ }^{148}$. Ellos «han enseñado a la Iglesia lo que han aprendido en ella» ${ }^{149}$, en manera que cuanto aprendieron, enseñaron, lo que de sus padres recibieron han transmitido a sus hijos, siempre basados en la Escritura y no en filosofías humanas ${ }^{150}$. «De aquí se sigue que cuando su voz concorde, constituye el eco fiel de la enseñanza de la Iglesia la que el cristiano debe aceptar aunque no llegue a comprenderla» ${ }^{151}$ del todo.

\subsubsection{La enseñanza de la Iglesia.}

Siendo la «regula fidei» el contenido mismo de la Escritura, de la verdad profesada desde los Apóstoles, ésta es la doctrina que debe ser enseñada por la Iglesia, precisamente en virtud de la «sana regula fidei». ${ }^{152}$. Esta es la función de la Iglesia para buscar «con el buen olor de la caridad» la unidad. En efecto, la «regula fidei» nos permite enseñar no otra cosa sino la exposición de las mismas Escrituras, ya que ella ha fijado las normas de nuestra doctrina ${ }^{153}$.

Por otra parte, el creyente «puede leer con discernimiento y aprobar lo que debe ser aprobado, o desaprobar lo que debe ser desaprobado en conformidad de la regla de la fe» ${ }^{154}$, y por tanto, la recta enseñanza de la fe es también seguro camino «alimentando como de leche de los santos misterios

147 Cf. P. ZMIRE, «Recherches...» art. cit.; A. TRAPÉ, «Teologia della Tradizione» en TRAPÉ, S. Agostino: Introduzione alla dottrina della grazia. I. Natura e Grazia, Roma 1987, 172-182; G. MASCHIO, «L'argomentazione...» art. cit.

148 «Isti [patres] episcopi sunt, docti, graves, sancti, veritatis acerrimi defensores adversus garrulas vanitates, in quorum ratione, eruditione, libertate, quae tria bona judici tribuisti, non potes invenire quod spernas... Talibus post Apostolos sancta Ecclesia plantatoribus, rigatoribus, aedificatoribus, nutritoribus crevit» Contra Iul. II 10,37: PL 44,700.

149 Contra Iul. op. imp. 1,117.

150 «Sed sanctos et in sancta Ecclesia illustres antistites Dei, non Platonicis et Aristotelicis et Zenonicis aliisque hujuscemodi, vel graecis vel latinis, quanquam et istis aliquos eorum omnes sacris litteris eruditos, nominatim sicut oportebat expressi (...) Quod invenerunt in Ecclesia, tenuerunt; quod didicerunt, docuerunt; quod a patribus acceperunt, hoc filiis tradiderunt» Contra Iul. II 10,34: PL 44,697.

151 A. TRAPÉ, «Teologia...» art. cit., p. 176.

152 De bapt. VI 25,47 .

153 De bono vid. 1,2 .

154 «Ac per hoc qui cum iudicio legunt et secundum regulam fidei adprobanda adprobant et inprobant inprobanda, etiamsi commendant memoriae quae inprobanda dicuntur, nulla venenata sententiarum pravitate laeduntur.» De anima et eius orig. II 17,23: CSEL 60,358 . 
(sacramentos); evitando con el temor de Dios las perversas costumbres, corrigiendo con la autoridad católica» ${ }^{155}$.

\subsection{El término «regula fidei» a nivel práctico.}

\subsubsection{Actitud existencial de la fe.}

La «regula fidei» tiene como objeto precisamente la fe en cuanto normada. De hecho, Agustín se refiere a ella en cuanto virtud o actitud existencial. Así parece indicarlo en las Confesiones cuando, hablando de su conversión, dice estar en la «regula fidei». En efecto, al interno del libro VIII de las Confesiones, Agustín nos habla de la lectura a los Rom. 13,13 ${ }^{156}$. Esta sentencia llegó «quasi luce securitatis infusa cordi meo omnes dubitationis tenebrae diffugerunt» ${ }^{157}$; a esta acción seguiría el acento de la lectura referida a Alipio: «Infirmum vero in fide recipite» (Rom. XIV,1). En este sentido, la fe no es sólo la acción de creer, sino que se trata del dinámico progreso espiritual ${ }^{158}$.

Concretamente, en cuanto a nuestro tema se refiere, Agustín dice de la esperanza que tiene el mismo objeto de la fe; que según la «regula catholica» ${ }^{159}$, de acuerdo a las Escrituras divinas, se denomina a la fe convicción de lo que no vemos (cf. Heb 11,1). Por tanto, la «regula fidei» es un movimiento existencial, porque «todo lo que profesamos en ella [«regula fidei»], lo profesamos desde la verdad y en la verdad en que vivimos, nos movemos y existimos» ${ }^{160}$. Así, la fe debe ser sostenida con templanza y de acuerdo a la Escritura que la ha fijado ${ }^{161}$.

155 De Bapt. V 27,38: CSEL 51,295.

156 Se refiere a la «regula lignea» (III 11,19) del sueño de Mónica en el 377, símbolo de la fe cristiana (= «regula fidei»), que según Agustín, Mónica «videbat enim illa mortem meam ex fide et spiritu». Como indicamos, la fe a la cual Agustín debería convertirse era la recta fe expresada con el término «regula fidei». Cf. 1.8.1.

157 Conf. VIII 12,30.

158 Cf. En. in Ps. 148,2.

159 «Fidei speique commune est. In epistóla quippe ad Hebraeos, qua teste usi sunt illustres catholicae Regulae defensores, fides esse dicta est convictio rerum quae non videntur (Hebr. XI,1). Quamvis quando se quisque non verbis, non testibus, non denique ullis argumentis, sed praesentium rerum evidentiae credidisse, hoc est, fidem accomodisse dicit, non ita videtur absurdus, ut recte reprehendatur in verbo, eique dicatur vidisti; ergo non credidisti... Sed melius hanc appellamus fidem [regulam fidei], quam divina eloquia docuerunt, earum scilicet rerum quae non videntur» Ench. 8,2: CCL 46,52.

160 «...habemus in regula fidei, et eam confitentes baptizamur. Et quidquid ibi confitemur, e veritate et in veritate confitemur, in qua vivimus et movemur et sumus» Sermo 362,7: PL 39,1614.

161 Cf. De bono vid. 1,2 . 


\subsection{2. «Boni mores vel regula fidei».}

Para el pensamiento agustiniano existe una intrínseca relación entre la fe y la moral. En efecto, vivir de acuerdo a la «regula fidei» ${ }^{162}$ es vivir en última instancia «en el camino supereminente de la caridad» ${ }^{163}$, ésta es la fragancia de la fe ${ }^{164}$ : «La fe es lo que primero subyuga el alma a Dios; luego los preceptos de vivir, con los cuales, cuando se guardan, se robustece la esperanza y aumenta la caridad» ${ }^{165}$, pues «a nosotros toca creer y esforzarnos con la voluntad, y a Dios pertenece dar a los que creen la facultad de obrar bien por el Espíritu Santo, que difunde en los corazones la caridad» ${ }^{166}$.

Repetidas veces Agustín afirma que necesitamos aprender la fe para poder vivir bien ${ }^{167}$, y en este sentido el término «regula fidei» se equipara a «regula disciplinae» ${ }^{168}$, «mensura fidei» ${ }^{169}$ o bien «regula saluberrima». Concretamente Agustín considera que tanto las buenas costumbres como la fe están contenidas en la Escritura, de tal forma que el cristiano tiene la seguridad de que su comportamiento corresponde a las «regulas saluberrimas tradunt», es decir, «los Apóstoles, que dieron saludabilísimas normas de vida, mandaban la forma como deban vivir entre sí según la condición de nación griega o judía; según la diferencia de estado, señor y de siervo, y según la diferencia de sexo, de hombres o mujeres. Lo mismo dígase de otras diferencias por el estado que ocurran. Antes que ellos lo estableció el Señor cuando dijo: Dad al César lo que es del César y a Dios lo que es de Dios» ${ }^{170}$. Así, aceptar la enseñanza para vivir bien es vivir de acuerdo a la «regula fidei» in «ordine vitae» ${ }^{171}$. Este problema viene tratado particularmente en la obra

162 El término «regula fidei» presenta un nexo intrínseco con los términos «mores vivendi, modum vivere, ordine vitae, bonos mores, praecepta vivendi, bonam vitam moresque, etc.».

163 «Ex hoc. numero [iustorum] quidam spiritualiter vivunt et supereminentem viam caritatis» De Bapt. V 27,38: CSEL 51,295.

164 Cf. Idem VI 25,47; In Io. ep. tract. 10,1 (PL 35,2054): «Fides christiani cum dilectione est».

165 De agone christ. 13,14: PL 40,209. Cf. In Io. ev. tract. 39,3 (CCL 36,346): «A fundamento fidei non recedamus, ut ad culmen perfectionis veniamus».

166 De praedest. Sanct. 3,7: PL 44,965.

167 Cf. De agone christ. 33,35; In Io. ev. tract. 18,7; De vera relig. 17,33.

168 «Iam vero ipse totius doctrinae modus, partim apertissimus, partim similitudinibus in dictis, in factis, in sacramentis, ad omnem animae instructionem exercitationemque, quid aliud quam rationalis disciplinae regulas implevit?» De vera relig. 17,33: CCL 32,207. Cf. De doc. christ. 4,40; Ep. 187,29.

169 De bono vid. 2.

170 Ep. ep. ad Gal. 28: CSEL 84,193.

171 «Alia sunt quae servamus in unitate fidei sine ulla distantia, et alia in ordine vitae huius tanquam in via, ne nomen Dei et doctrina blasphemetur» Idem. Cf. De Gen. ad Lit. XII 14,28. Otra finalidad es la construcción de la caridad: De Bapt. VI 25,47; De Symb. ad cath. 2,4 . 
De fide et operibus, cuando se plantea la cuestión de la unidad de la fe y de las costumbres ${ }^{172}$. La respuesta de Agustín es que es necesario una instrucción previa al bautismo de manera que el cristiano viva íntegramente ${ }^{173}$. Por otra parte, ésta era la intención explícita de Agustín al escribir esta obra, así como De agone christiano ${ }^{174}$.

\subsection{3. «Regula fidei»y «regula falsa».}

En su aspecto práctico, la «regula fidei» es garantía de la doctrina correcta o la recta doctrina ${ }^{175}$. Este criterio de ortodoxia permite al cristiano la posibilidad de profesar lo que se debe creer. En contradicción a la «regula falsa» de los herejes, pues ella es una norma personal, no eclesial, de una voluntad necia ${ }^{176}$, está la «regula fidei» que adiestra y dirige la mente humana ${ }^{177}$, previniendo contra el error doctrinal. A esta idea podemos notar el uso de la imagen plástica del camino recto, varias veces usado por el mismo Agustín. En efecto, caminar en la «regula fidei» es progresar en la fe, tener una clara inteligencia, no endurecerse en una defensa contenciosa ${ }^{178}$, sino bajo la autoridad de la Iglesia que expone la fe verdadera y católica ${ }^{179}$. En última instancia, la verdad es Cristo mismo. «El fin de nuestra intencionalidad es Cristo, ya que aunque personalmente nos esforcemos, en él nos perfeccionamos, y por él somos perfeccionados; y toda nuestra perfección es ésta: llegar a él. El, pues, nos propuso en esta vida un modelo del vivir, y nos dará en la vida futura un premio del vivir» ${ }^{180}$. Luego, en tanto se aparta de esta Verdad o se malinterpreta se ataca la integridad de la norma de fe con doctrinas perversas. Prácticamente, como hemos señalado, la herejía se ori-

172 Cf. De fide et op. 6,$9 ; 7,10$.

173 Idem 7,11. Recordamos que en este texto el término «regula fidei» aparece dos veces (cf. 1.2.).

174 «Interea missa sunt mihi a quibusdam fratribus laicis quidem, sed divinorum eloquiorum studiosis, scripta nonnulla, quae ita distinguerent a bonis operibus christianam fidem, ut sine hac non posse, sine illis autem posse perveniri suaderetur ad aeternam vitam. Quibus respondens librum scripsi, suius nomen est de Fide et operibus. In quo disputavi non solum quemadmodum vivere debeant gratia Christi regenerati, verum etiam quales ad lavacrum regenerationis admitti» Retracta. 2,38: CCL 57,121. Cf. Idem 2,3.

$175 \mathrm{Cf}$. De anima et eius orig. II 17,23.

176 Contra adv. leg. et proph. II 9,34. La misma idea la encontramos Contra Faust. manich. 11,2 (CSEL 25,315): «Tu es ergo regula veritatis?» en este sentido «regula veritatis» es el "Corpus Paulinum", luego la santa Escritura.

177 De Trin. $15,49$.

178 Ep. 187,29.

179 Ep. 217,15. Sobre todo En. in Ps. 85,15; In Io. ev. tract. 69,1-2; $98,7$.

180 En. in Ps 56,2: CCL 39,695. 
gina por la poca atención que se pone en la lectura o interpretación del Símbolo de la fe y en las Escrituras divinas ${ }^{181}$.

\subsection{4. «Regula fidei in unitate fidei ab unitate fidei».}

Podemos afirmar, siguiendo el pensamiento de San Agustín, que la «regula fidei» tiene como objetivo práctico y funcional el salvaguardar la unidad de la fe católica, difundida por todo el orbe ${ }^{182}$. El comentario de la Carta a los Galatas 28 es elocuente al manifestar este sentido. Comentando Rom 8,23.10. expresa esta idea:

$$
\begin{array}{lc}
\text { ab unitate fidei } \rightarrow \\
\text { (propter iustitiam } \\
\text { fidei) }
\end{array} \quad \begin{aligned}
& \text { regulas saluberrimas } \\
& \text { (tradunt) }
\end{aligned} \quad\left\{\begin{array}{l}
\text { in unitate fidei } \\
0 \\
\text { in ordine vitae }
\end{array}\right.
$$

De hecho afirma categóricamente: «Nam nunc quamvis primitias habentes spiritus, qui vita est, propter iustitiam fidei,... ab unitate fidei,... et apostoli praecipiunt, qui etiam regulas saluberrimas tradunt... Alia sunt enim quae servamus in unitate fidei sine ulla distantia, et alia in ordine vitae huius tamquam in via, ne nomen Dei et doctrina blasphemetur» ${ }^{183}$.

Como podemos apreciar, sea que se trate de la praxis de vida, de la doctrina cristiana, del Símbolo de la fe, de la Escritura, etc., prácticamente todo debe conformarse siempre «secundum regula fidei» y no «contra» ella. En este sentido se podría hablar de la «regula fidei» como sinónimo del «sensus fidelium».

\section{Conclusiones}

1. El término «regula fidei» en el pensamiento teológico de San Agustín, como venía usado ya por Tertuliano y Orígenes, indica un criterio formal sobre la normatividad de la fe para interpretar las Escrituras y combatir la herejía, en sentido polémico o apologético. Sin embargo, de acuerdo a nuestra investigación podemos afirmar que, aunque si en el contexto polémico viene reclamado 20 veces, el término representa solo un poco más de un cuarto de la totalidad presente en toda la obra agustiniana. Esto significa

181 «Neque enim natae sunt haereses, et quaedam dogmata perversitatis illaqueantia animas et in profundum praecipitantia, nisi dum Scripturae bonae intelliguntur non bene, et quod in eis non bene intelligitur, etiam temere et audacter asseritur» In Io. ev. tract. 18,1: CCL 36,180 (cf. idem 98,7). «Non ergo vobis subrepat quorumdam sententia minus attentorum in regulam fidei et in scripturarum oracula divinarum» Sermo 186,2: PL 38,999.

182 Cf. De vera relig. 6, 10-11.

183 Exp. ep. ad Gal. 28: CSEL 84,93. 
que, en Agustín el término «regula fidei» recibe un enriquecimiento en cuanto a su significado.

De hecho, el término viene usado por Agustín al menos 71 veces, predominando en línea polémica contra los Pelagianos (12 v.), Donatistas (3 v.), Marcionitas (2 v.), Arrianos y Maniqueos. Considerablemente fue usado en Los Comentarios al Evangelio de Juan (6 v.), La Ciudad de Dios (4 v.), en las Homilías (8 v.) y en Los Comentarios a los Salmos (4 v.); así como en los escritos exegéticos como Sobre la Doctrina Cristiana (4 v.), o dogmáticos como en La Trinidad (4 v.). Inclusive se encuentra empleado en un contexto moral y hasta personal como en Las Confesiones.

2. El campo semántico en el que se presenta el término «regula fidei» está enmarcado por los términos dinámicos de la exégesis bíblica, la tradición, la profesión de fe y del progreso dogmático. Este dinámico vocabulario da como resultado que, en la mayoría de los casos, el término viene apoyado por un calificativo que lo determina con una connotación siempre diversa, y por tanto, se relaciona distinta y radicalmente, es decir, "según" o "contra".

3. El término «regula fidei» presenta al menos tres niveles de comprensión:

a. A nivel exegético el término «regula fidei» se refiere al criterio objetivo de interpretación de la Sagrada Escritura; por tanto, se entiende como «veracidad» exegética. Pero al mismo tiempo, es criterio de recepción del canon bíblico, el cual ha sido aceptado por todos en la Iglesia desde los tiempos apostólicos. En este sentido, «regula fidei» apela a la autoridad contenida en sí por su carácter católico y apostólico.

b. A nivel dogmático el término «regula fidei» indica ante todo el Símbolo de la fe o sus artículos definidos por la Iglesia y enseñados íntegramente a los catecúmenos para que sean profesados siempre. En este contexto se trata de la «verdad» católica (dogma) sobre Dios, verdad que se debe creer, aceptar y profesar sobre todo en la Liturgia, para llevarla siempre en el corazón y en la memoria.

«Regula fidei» es la doctrina sobre Dios, sobre Jesucristo y sobre la Iglesia; por tanto, ella misma es el objeto formal de la fe, enseñada así por los Padres de la Iglesia por quienes se ha comunicado y la misma «regula» sigue comunicándose por medio de la enseñanza o magisterio de la Iglesia.

c. A nivel práctico el término «regula fidei» indica el recto comportamiento (ortopraxis cristiana) y la recta doctrina (ortodoxia católica). Indica la garantía de vivir en comunión eclesial, por lo que exige «el buen olor de la caridad» con el cual todos edificamos la unidad de la Iglesia ya en orden a la 
unidad de la fe, ya en orden de vida, es decir, alejándose de la herejía y observando la disciplina canónica, litúrgica o escriturística. 'Así, «regula fidei» es el sentido común de los fieles («sensus fidelium») sobre el creer y actuar del cristiano al interno o fuera de la Iglesia.

Mario MENDOZA 